\title{
INVASIVE PNEUMOCOCCAL DISEASE IN NEONATES PRIOR TO PNEUMOCOCCAL CONJUGATE VACCINE \\ USE IN SOUTH AFRICA: 2003 - 2008
}

\author{
By \\ Krishnee Moodley (MBChB) (FCPath SA(Micro)) \\ Submitted in partial fulfillment of the academic requirements for the degree MMed \\ (Micro), in the Department of Microbiology, School of Laboratory Medicine, College \\ of Health Sciences, University of KwaZulu-Natal, Durban, 2018
}

As the candidate's supervisors we have approved this thesis for submission

Name: Prof Y Coovadia

Signed:

Date: 15 March 2018

Date of submission: 15 March 2018
Prof Anne von Gottberg

Signed:

Date: 15 March 2018 


\section{INVASIVE PNEUMOCOCCAL DISEASE IN NEONATES \\ PRIOR TO PNEUMOCOCCAL CONJUGATE VACCINE USE}

IN SOUTH AFRICA: $2003-2008$

By

Krishnee Moodley (MBChB) (FCPath SA(Micro))

Submitted in partial fulfillment of the acadenic requirements for the degree MMed (Micro),

in the Department of Microbiology, School of Laboratory Medicine, College of Health

Sciences, University of KwaZulu-Natal, Durban, 2018

As the candidate's supervisors we have approved this thesis for submission

Name: Prof Y Coovadia

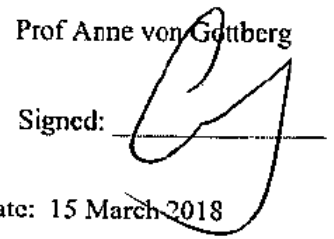

Date: 15 March 2018

Date: 15 March 2018

Date of submission: 15 March 2018 


\section{DECLARATION:}

I, Krishnee Moodley, declare that:

(i) The research reported in this dissertation, except where otherwise indicated, is my original work.

(ii) This dissertation has not been submitted for any degree or examination at any other University.

(iii) This dissertation does not contain other persons' data, pictures, graphs, or other information, unless specifically acknowledged as being sourced from other persons.

(iv) This dissertation does not contain other persons' writing, unless specifically acknowledged as being sourced from other researchers. Where other written sources have been quoted then:

a) Their words have been re-written but the general information attributed to them has been referenced.

b) Where their exact words have been used, their writing has been placed inside quotation marks, and referenced.

(v)Where I have reproduced a publication of which I am an author, co-author, or editor, I have indicated in detail which part of the publication was written by myself alone and have fully referenced such publications.

(vi) This dissertation does not contain text, graphics or tables copied and pasted from the internet, unless specifically acknowledged, and the source being detailed in the dissertation and in the References sections. 


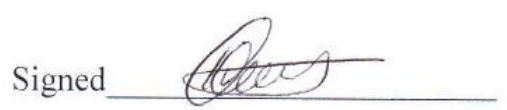

Signed
Date:

$15 / 0312018$

iv 


\section{ACKNOWLEDGEMENTS}

I am grateful to my supervisors, Prof Y Coovadia and Prof Anne von Gottberg for their patience and guidance with my MMed. I am also very appreciative of the support and guidance from Dr M Archary, and my HOD, Dr AKC Peer.

My personal support system, my husband, Collin, my amazing children, Akhilan and Sudhayan, and my always encouraging, quietly motivating parents, and friends, have been an integral part of this journey and I am ever grateful to them all. 


\section{TABLE OF CONTENTS}

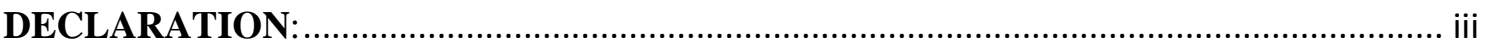

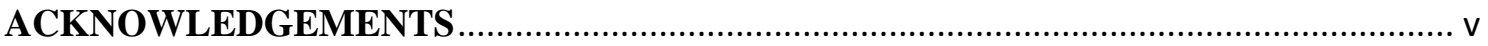

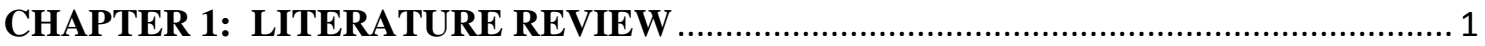

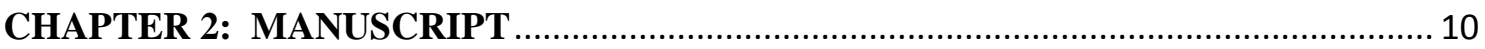

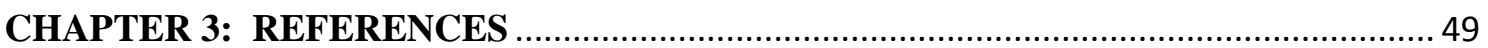

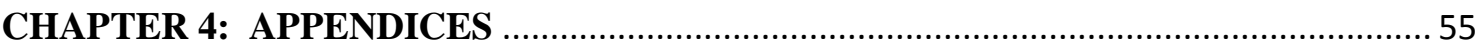




\section{CHAPTER 1: LITERATURE REVIEW}

\section{Introduction}

3 The global under five mortality rate was estimated to be 43 per 1000 live births in 2015 .

4 The highest rate was noted in Sub Saharan Africa, with infectious diseases implicated as

5 the leading cause of mortality in children under 5 years of age [1]. Pneumonia was the

6 second commonest cause of death in children under 5 years of age [1]. Streptococcus

7 pneumoniae accounted for approximately $11 \%$ of childhood deaths in the under five-

8 year age group, worldwide [2]. This encapsulated Gram-positive diplococcus is the

9 commonest bacterial cause of pneumonia, otitis media, septicemia and meningitis in this

10 age group [3].

11 Invasive pneumococcal disease (IPD) is defined as "morbidity associated with the

12 isolation of pneumococci from a normally sterile body site, such as the blood stream, or

13 those secondary to blood stream spread, e.g. meningitis or septic arthritis" [4].

14 Incidence rates for IPD are highest in young children ( $<2$ years of age) and the elderly >

1565 years, in patients with chronic illnesses such as cardiac failure and chronic

16 obstructive pulmonary disease, as well as HIV infection and splenectomy [5].

17 In South Africa, HIV infection has been reported to be a significant risk factor for IPD

18 in children and adults $[6,7]$.

19 Invasive pneumococcal disease in the neonate

20 The first known case of IPD in a neonate was reported in 1889 in Paris [8]. Since then

21 several case series and case reports have described neonatal IPD in different parts of the

22 world [8, 9]. Billings et al reported an estimated global incidence of 36 per 100000 
23 live births, at a time when most countries had not introduced the pneumococcal vaccine

24 into their childhood immunization programs [10]. In their analyses, they observed that

25 there was a paucity of data on neonatal IPD in low- to middle-income countries

26 (LMICs) [10]. The incidence of neonatal IPD in South Africa has not previously been

27 documented.

\section{Clinical features and outcome}

29 Neonatal sepsis is defined as "early-onset" if it occurs at $<7$ days of age and "late-onset"

30 if it occurs at $\geq 7<28$ days of age [11]. Early-onset disease (EOD) in neonates may be

31 acquired in utero by hematogenous spread or intrapartum, either by ascending infection

32 or during passage through the birth canal in the presence of vaginal colonization [12,

33 13]. Late-onset disease (LOD) is acquired postnatally via horizontal spread from the

34 mother, family members or other caregivers $[12,13]$.

In one of the largest case series of neonatal IPD, Gomez et al reported a preponderance of early-onset disease [8]. This was similar to the findings by Geelen et al in the Netherlands [14], and Soto-Noguerón A et al in Mexico [15]. In contrast, Hoffman et al reported on a series of 29 neonates with IPD wherein they found that most cases presented in the third week of life [9] (Table 1). These differences may be due to differences in at-risk populations, socio-economic conditions and access to maternal and child healthcare [15].

The clinical presentation of IPD in neonates included pneumonia, meningitis, bacteremia, otitis media and osteomyelitis $[8,9,16]$. Sepsis was reported to be the predominant clinical presentation in the early-onset group and meningitis in the lateonset group [9]. Neonatal IPD was associated with a high mortality rate, up to $50 \%$ in 
one case series $[14,16]$ (Table 1), with the reported case fatality ratio being highest in

47 the early-onset group [8].

The risk for IPD among children < 1years of age has been found to be greater in HIVinfected than HIV-uninfected children in South Africa [6]. The risk for IPD was also found to be higher among infants $<6$ months of age who were HIV-exposed but not infected, compared to those who were HIV-unexposed and uninfected, in South Africa

[17]. This increased risk may also be present among neonates, but has not been reported to date, in South Africa or in other parts of the world.

\section{Serotype distribution}

Based on the capsular polysaccharide antigen, there are $>90$ S. pneumoniae serotypes

[18]. The serotypes differ in terms of their ability to colonize the nasopharynx, cause invasive disease, association with clinical syndromes, antimicrobial resistance patterns, preponderance in different age groups as well as ability to cause outbreaks [19]. "Pediatric" serotypes have been described as those serotypes most frequently isolated from children $<5$ years old and most frequently associated with antimicrobial resistance [19]. These include serotypes: 4, 6B, 9V, 14, 18C, 19F and 23F (PCV7 serotypes) as well as serotypes 6A and 19A [19].

The most frequently isolated serotypes prior to the introduction of the pneumococcal conjugate vaccines into national immunization schedules were the seven serotypes included in the seven valent pneumococcal conjugate vaccine (PCV7). These seven serotypes, 4, 6B, 9V, 14, 18C, 19F, and 23F, accounted for $60-75 \%$ of IPD in children

67 in different parts of the world $[6,20]$. In 2010 vaccines providing coverage against additional serotypes, the 10-valent (PCV10) and 13-valent (PCV13) vaccines, were 
introduced [21]. The PCV7 was introduced as part of the routine pediatric immunization schedule in South Africa in 2009. However, in 2011 the PCV7 was replaced by the PCV13, which added serotypes 1, 3, 5, 6A, 7F, 19A to the serotypes covered.

In England, prior to PCV introduction, the serotypes implicated in neonatal IPD were reported to be those more frequently isolated in older children and young adults [22]. In infants $<90$ days of age PCV 7 and PCV 13 serotypes accounted for $44 \%$ and $63 \%$ of serotyped isolates in the same study [22]. Similar coverage was noted in Mexico in children $<=60$ days of age, also in the prevaccine era [15]. Hoffman et al reported $75 \%$ of IPD was due to PCV 7 serotypes, in the USA [9]. The most frequent serotypes in neonatal IPD were $1,3,5,12,7 \mathrm{~F}, 19 \mathrm{~F}$ [ 9, 15, 20 ] (Table 1). These are all vaccine serotypes included in the PCV13. However, serotypes 3, 5 and 7F have been reported as uncommon causes of IPD in South African children $<5$ years of age [6].

82 Neonates may be protected from IPD by the indirect effects of PCV, or by maternal immunization. Herd protection with use of PCV occurs through vaccinated individuals who are less likely to carry vaccine-type pneumococci, thus reducing transmission and conferring protection to those who are unimmunized [23]. The decrease in neonatal IPD in England and Wales post-PCV introduction suggests a role for herd protection

87 [22]. Maternal immunization strategies have been explored by investigators in Brazil $[24,25]$. However, there is no current recommendation for routine immunization of pregnant mothers against pneumococcus, as there is insufficient evidence that such 


\section{Antimicrobial susceptibility}

92 The first clinical isolate of penicillin non-susceptible S. pneumoniae was reported in 931967 in Papua, New Guinea [28]. Since then numerous reports have documented the

94 clonal spread of multidrug-resistant S. pneumoniae, in South Africa, as well as globally

$95[29,30]$. On a global level, the serotypes associated with penicillin resistance were $9619 \mathrm{~A}, 19 \mathrm{~F}, 35 \mathrm{~B}, 6 \mathrm{~A}, 6 \mathrm{~B}, 23 \mathrm{~A}, 9 \mathrm{~V}, 15 \mathrm{~A}$, and 14 [31]. Multidrug-resistance (MDR) is

97 defined as resistance to antimicrobials in three or more classes [32]. In 2008, the incidence of MDR IPD was highest in the <1-year age group [6]. In South Africa, prior to the introduction of the conjugate vaccines, the strongest independent risk factor for multidrug resistant IPD was IPD caused by PCV13 serotypes [33].

In contrast, neonatal IPD has been associated with penicillin-susceptible isolates (Table 1). This has been attributed to the fact that the commonest serotypes implicated in neonatal IPD are infrequently associated with antimicrobial resistance $[8,9,22]$.

104 International guidelines for empiric therapy of suspected neonatal sepsis include the use 105 of ampicillin and gentamicin, or a third generation cephalosporin [34]. Such regimens would therefore provide adequate coverage for neonates with IPD. 


\section{Summary}

108 Neonatal IPD has been well-described in high-income countries, but there is a paucity 109 of data in LMICs. This is the first study in South Africa that aims to provide baseline 110 data on the pre-vaccine incidence, clinical features, serotype distribution and

111 antimicrobial susceptibility of neonatal IPD. This study provides a background upon

112 which to interpret changes that may occur in the post-vaccine era in neonates. This

113 study also provides useful baseline data for other LMICs who are still rolling out the $114 \quad \mathrm{PCV}$ in their countries. 
Table 1: Summary of neonatal invasive pneumococcal disease in different countries, 1975 - 2013

\begin{tabular}{|c|c|c|c|c|c|c|c|c|c|c|}
\hline Author & Setting & Design & $\begin{array}{c}\text { Study } \\
\text { population }\end{array}$ & EOD & LOD & PCV7 $^{a}$ & PCV13 $^{b}$ & $\begin{array}{c}\text { Predominant } \\
\text { serotypes }\end{array}$ & $\begin{array}{c}\text { Penicillin } \\
\text { susceptibility }\end{array}$ & $\begin{array}{c}\text { Case } \\
\text { fatality } \\
\text { ratio } \\
\text { (CFR) }\end{array}$ \\
\hline & & & $\mathbf{N}$ & $\%(n)$ & $\%(n)$ & $\%(n)$ & $\%(n)$ & & $\%(n)$ & $\%(n)$ \\
\hline Gomez M et al [8] & Ohio, USA & $\begin{array}{l}\text { 1966-1998; Case reports and } \\
\text { literature review; IPD, Age <30 days }\end{array}$ & 101 & $86(87)$ & 14(14) & & & 3,19 & & $48(46)$ \\
\hline $\begin{array}{l}\text { Hoffman JA et al } \\
{[9]}\end{array}$ & USA & $\begin{array}{l}\text { 1993 - 2001; Pediatric Multicentre } \\
\text { Pneumococcal Surveillance Group; } \\
\text { IPD, age } \leq 30 \text { days }\end{array}$ & 21 & $14(3)$ & $86(18)$ & $75(15)$ & & $1,3,5,12,19$ & $80(16)$ & $14(3)$ \\
\hline $\begin{array}{l}\text { Malhotra A et al } \\
{[12]}\end{array}$ & $\begin{array}{l}\text { Melbourne, } \\
\text { Australia }\end{array}$ & 2 years, 3 hospital sites & 4 & $100(4)$ & 0 & $25(1)$ & $50(2)$ & & $50(2)$ & 0 \\
\hline $\begin{array}{l}\text { Geelen SBM et al } \\
{[14]}\end{array}$ & The Netherlands & 1975 - 1988; Neonatal ICU & 7 & $100(7)$ & 0 & & & 3,19 & & $43(3)$ \\
\hline $\begin{array}{l}\text { Soto-Noguerón A } \\
\text { et.al [15] }\end{array}$ & Mexico & $\begin{array}{l}2000-2014 ; \\
\text { National, PCV7 introduced in } 2006 \text {; } \\
\text { IPD and NIPD } \text {, age }<60 \text { days }\end{array}$ & $\mathrm{IPD}=69$ & $26(18)$ & $74(51)$ & $34(43)$ & $64(80)$ & & & $13(7)$ \\
\hline
\end{tabular}


Table 1: Summary of neonatal invasive pneumococcal disease in different countries, 1975 - 2013

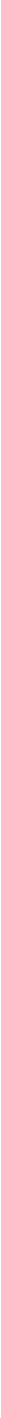


Table 1: Summary of neonatal invasive pneumococcal disease in different countries, $1975-2013$

\begin{tabular}{|c|c|c|c|c|c|c|c|c|c|c|}
\hline Author & Setting & Design & $\begin{array}{c}\text { Study } \\
\text { population }\end{array}$ & EOD & LOD & PCV7 $^{a}$ & PCV13 $^{b}$ & $\begin{array}{c}\text { Predominant } \\
\text { serotypes }\end{array}$ & $\begin{array}{c}\text { Penicillin } \\
\text { susceptibility }\end{array}$ & $\begin{array}{c}\text { Case } \\
\text { fatality } \\
\text { ratio } \\
\text { (CFR) }\end{array}$ \\
\hline & & & $\mathbf{N}$ & $\%(n)$ & $\%(n)$ & $\%(n)$ & $\%(n)$ & & $\%(n)$ & $\%(n)$ \\
\hline Lagos $\mathrm{R}$ et al [37] & Santiago, Chile & $\begin{array}{l}1994 \text { - 2007; Metropolitan region; } \\
\text { IPD, age } 0 \text { - } 5 \text { months }\end{array}$ & 430 & & & & 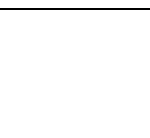 & $\begin{array}{c}1,5,14,19 \mathrm{~F} \\
19 \mathrm{~A}\end{array}$ & 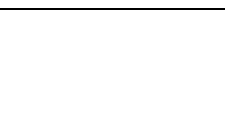 & $13(57)$ \\
\hline Bas AY et al [38] & Turkey & $\begin{array}{l}1999 \text { - 2008: Tertiary hospital ICU - } \\
\text { pneumococcal meningitis, age < } 30 \text { days }\end{array}$ & 8 & $13(1)$ & $87(7)$ & & & & $100(8)$ & $50(4)$ \\
\hline Olarte et al [39] & Utah & $\begin{array}{l}\text { 1997-2010; Single tertiary } \\
\text { children's hospital; PCV7 introduced } \\
\text { 2001; IPD, age } 1 \text { - } 90 \text { days }\end{array}$ & $\begin{array}{c}36 \\
\text { Age }<30 \\
\text { days: } \\
\mathrm{N}=6\end{array}$ & $33(2)$ & $67(4)$ & $19(7)$ & $69(25)$ & $7 \mathrm{~F}$ & & $50(3)$ \\
\hline Mount V et al [40] & New Zealand & $\begin{array}{l}\text { 2009 - 2013; National surveillance; } \\
\text { IPD; PCV7 introduced in 2008; } \\
\text { age <90 days }\end{array}$ & $\begin{array}{c}29 \\
\text { Age }<30 \\
\text { days: } \\
\mathrm{N}=19\end{array}$ & $47(9)$ & $53(10)$ & $26(5)$ & $74(14)$ & 19F, 19A, 3 & $89(17)$ & $11(1)^{\mathrm{f}}$ \\
\hline
\end{tabular}




\section{Footnotes:}

Abbreviations - IPD = invasive pneumococcal disease; PCV = pneumococcal conjugate vaccine; EOD = early-onset disease $(<7$ days old $)$; LOD = lateonset disease $(\geq 7-28$ days old $)$; $\mathrm{CFR}=$ case fatality ratio; $\mathrm{ICU}=$ intensive care unit

${ }^{\mathrm{a}}$ - seven -valent PCV; ${ }^{\mathrm{b}}$ - thirteen -valent PCV $;{ }^{\mathrm{c}}-\mathrm{NIPD}=$ non-invasive pneumococcal disease $;{ }^{\mathrm{d}}-\mathrm{EOD}$ was aged $0-10$ days; ${ }^{\mathrm{e}}-\mathrm{LOD}$ was $>10-<89$ days; ${ }^{\mathrm{f}}$ - only EOD outcome was reported in this study 


\section{CHAPTER 2: MANUSCRIPT}

116 Title: Invasive pneumococcal disease in neonates prior to pneumococcal conjugate

117 vaccine use in South Africa: 2003 - 2008

118 This manuscript has been prepared according to the instructions for authors for

119 submission to Pediatric Infectious Diseases Journal (PIDJ). The manuscript has been

120 reviewed by PIDJ reviewers and corrections have been made. A revised manuscript has

121 been submitted to PIDJ and I am currently awaiting feedback from the editors.

122 


\section{Title page}

\section{Invasive pneumococcal disease in neonates prior to pneumococcal conjugate} vaccine use in South Africa: 2003 - 2008

Authors: Krishnee Moodley ${ }^{1,2}$, Yacoob Coovadia ${ }^{3}$, Cheryl Cohen $\mathrm{PhD}^{4,5}$, Susan

Meiring $^{6}$, Sarona Mhlanga ${ }^{4}$, Linda De Gouveia ${ }^{4}$, Claire von Mollendorf ${ }^{4,5}$, Penny

Crowther-Gibson ${ }^{6}$, Vanessa Quan ${ }^{6}$, Brian Eley MD ${ }^{7}$, Gary Reubenson MD ${ }^{8}$, Trusha

Nana ${ }^{9}$, Anne von Gottberg $\mathrm{PhD}^{10}$

1. Microbiology, Lancet Laboratories, Kwa-Zulu Natal, South Africa

2. Honorary research fellow, Antimicrobial Research Unit, College of Health Sciences, University of Kwa-Zulu-Natal, Durban, South Africa

3. Department of Medical Microbiology, Nelson R Mandela School of Medicine, University of Kwa-Zulu Natal, Durban, South Africa

4. Centre for Respiratory Diseases and Meningitis, National Institute for Communicable Diseases of the National Health Laboratory Service, Johannesburg, South Africa

5. School of Public Health, Faculty of Health Sciences, University of the Witwatersrand, Johannesburg, South Africa

6. Division of Public Health Surveillance and Response, National Institute for Communicable Diseases of the National Health Laboratory Service, Johannesburg, South Africa

7. Pediatric Infectious Diseases Unit, Red Cross War Memorial Children's Hospital, Department of Pediatrics and Child Health, University of Cape Town, Cape Town, South Africa 
8. Rahima Moosa Mother and Child Hospital, Department of Pediatrics and Child Health, Faculty of Health Sciences, University of the Witwatersrand,

Corresponding author:

154

Financial disclosures:

email - krishnee.moodley@ lancet.co.za;

moodleykrishnee@gmail.com

$$
\text { Telephone - work - } 031 \text { 3086610; home - } 031 \text { 4631224; cell - }
$$

0824642494

$$
\text { Fax }-0313086600
$$

1. Cheryl Cohen - this work was supported by the National Institute for Communicable Diseases, of the National Health Laboratory Service and the US Centers for Disease Control and Prevention (co-operative agreement number: 5U51IP000155). In addition, Cheryl has received grants from Sanofi and Parexel, unrelated to the current manuscript. 
2. Claire von Mollendorf - has received speaker funding from Pfizer in the last 3 years, unrelated to the current manuscript.

170 Conflicts of interest: Nil

171 Keywords: Neonates, invasive pneumococcal disease, South Africa, Streptococcus

172 pneumoniae, pneumococcal conjugate vaccine

173 Cover title: Neonatal IPD in South Africa in the pre-vaccine era: 2003-2008

174 Running head title: Neonatal IPD in South Africa: 2003 - 2008 
175 Abstract

176 Background: Neonatal invasive pneumococcal disease (IPD) in developing countries is

177 poorly described. We provide a baseline description of neonatal IPD in South Africa,

178 prior to implementation of the seven-valent pneumococcal conjugate vaccine (PCV7) in 1792009.

Methods: Data from children (age $\leq 2$ years) with IPD (pneumococcus identified from a normally sterile specimen) from January 2003 - December 2008 were extracted from a national laboratory-based surveillance database. Clinical and laboratory characteristics of IPD amongst neonates (0-27 days old) was compared to IPD amongst young children ( $\geq 28$ days $\leq 2$ years). Early-onset IPD (EOD) (0 - 6 days old) was compared with lateonset IPD (LOD) ( $\geq 7-27$ days old). Isolates were serotyped using the Quellung reaction.

Results: Overall 27630 IPD cases were reported. Of the 26277 (95\%) with known ages, $6583(25 \%)$ were $\leq 2$ years of age, of which $4.5 \%(294 / 6583)$ were neonates. The estimated annual incidence of neonatal IPD in 2008 was 5 per 100000 live births. Fifty-one percent of neonates with IPD presented with EOD. Case-fatality ratios (CFR) were high in both groups, $31 \%(28 / 89)$ in neonatal IPD vs 26\%(614/2383) in nonneonatal IPD $(\mathrm{p}=0.18)$. Among neonates the meningitis cases $(15 / 37,41 \%)$ were associated with the highest CFR. The thirteen-valent pneumococcal conjugate vaccine (PCV13) serotypes accounted for 69\% (134/194) of neonatal IPD isolates.

Conclusions: Pneumococcal neonatal disease in South Africa was not uncommon prior to PCV introduction, and is associated with a high CFR. The indirect effect on neonatal IPD of PCV rollout requires further evaluation. 
Neonatal IPD in South Africa: 2003 - 2008

198

Introduction

199

200

201

202

203

204

205

206

207

208

209

210

211

212

213

214

215

216

217

218

219

Invasive pneumococcal disease (IPD) is a significant cause of mortality and morbidity in children under five years of age, with the highest incidence (an estimated $75 \%$ of reported cases) in children $\leq$ two years of age $[1,2]$. An estimated $6-8 \%$ of globally reported IPD in children under five years of age occurred in under two month old infants [3].

The estimated global incidence of neonatal IPD in 2010 was 36 per 100000 live births, when many low-income countries were still not using the pneumococcal conjugate vaccine (PCV) [4]. This incidence however, varies markedly from low- and middleincome countries (LMIC) such as Chile, with an incidence of 59 per 100000 population [5], and high-income countries such as the USA and England and Wales, with an incidence of $11-13$ per 100000 live births [6, 7]. The incidence of neonatal IPD in South Africa, a middle-income country with a high maternal HIV infection rate, is not known [8].

Neonates are at risk for IPD via exposure to Streptococcus pneumoniae either during passage through the birth canal, by hematogenous spread in utero, or by horizontal spread from caregivers and siblings $[9,10]$. Neonatal IPD has been categorized as early-onset disease (EOD) or late-onset disease (LOD) based on presentation in the first seven days of life or later [11]. The presenting clinical features are non-specific [12]. Neonatal IPD isolates are reported to be more susceptible to antimicrobials than those found in older children [13]. The case fatality ratio (CFR) in neonatal IPD may be high, up to $50 \%$ [12]. 
Neonatal IPD in South Africa: 2003 - 2008

220 The seven-valent PCV (PCV 7) was introduced into the routine immunization schedule

221 in South Africa in 2009, and replaced by the thirteen-valent PCV (PCV13) in 2011.

222 Globally, most of the serotypes in neonatal IPD, serotypes 1, 3, 5, 12, 7F, are included

223 in the PCV13 $[13,14]$. Herd protection with use of PCV occurs through vaccinated

224 individuals who are less likely to carry vaccine-type pneumococci, thus reducing

225 transmission and conferring protection to those who are unimmunized [15]. Neonates

226 may be protected by maternal antibodies or by the indirect effects of PCV. There is

227 currently no recommendation for routine immunization of pregnant mothers against

228 pneumococcus $[16,17]$. The serotype distribution of neonatal IPD in South Africa and

229 other developing countries prior to the introduction of PCV is largely unknown [4].

230 This study describes neonatal IPD, in the pre-PCV era, in South Africa, with the aim of

231 providing baseline data to assist the interpretation of changes, with respect to incidence,

232 serotype distribution, clinical presentation, and antimicrobial susceptibility, that may

233 have occurred since the introduction of PCV. In view of the lack of pre-vaccine data on

234 neonatal IPD in LMICs, the findings in this study are also of value to other countries

235 who are still in the introductory phases of PCV implementation [4]. 
Neonatal IPD in South Africa: 2003 - 2008

236

Methods

237

Ethics

Ethical clearance was obtained from the Biomedical Research Ethics Committee of the

University of KwaZulu-Natal (BE 012/010). In addition, ethical clearance and permission to conduct laboratory-based and enhanced surveillance in South Africa for this study was obtained from the Health Research Ethics Committee (Human), University of Witwatersrand (Clearance number M02-10-42); the University of Stellenbosch Health Research Ethics Committee (Reference number N04/01/0021), the National Institute for Communicable Diseases Research Committee (Clearance number M060449); and the South African Department of Health (Reference H2/12/8).

\section{Surveillance}

247 Surveillance data were extracted from an ongoing, active, laboratory-based surveillance system, performed through GERMS-SA (Group for Enteric, Respiratory and Meningeal disease Surveillance in South Africa), commencing in 1999 and enhanced in 2003 [18]. GERMS-SA is a national laboratory-based surveillance system that collects data and isolates from both the public and private sector laboratories in South Africa. Their enhanced surveillance sites employ surveillance officers who perform follow-up on reported cases and populate case report forms (CRFs)with additional data such as admission dates, clinical diagnosis, outcome and HIV status. The enhanced surveillance (ES) stabilized in 2005, and continued through 2008. Reports and pneumococcal isolates from individuals with laboratory-confirmed IPD were submitted

257 from > 130 laboratories (public and private sector) nation-wide to the National Institute 258 for Communicable Diseases (NICD) in Johannesburg, South Africa. Each report 
Neonatal IPD in South Africa: 2003 - 2008

259

260

261

262

263

264

265

266

267

268

269

270

271

272

273

274

275

276

277

278

279

280

contained patient demographic data including age, sex, date of specimen collection and specimen type. Additional information including admission date, HIV status, clinical diagnosis, and outcome were collected only at the ES sites, 25 hospital-based laboratories in the nine provinces. Surveillance officers documented outcome as inhospital mortality, or recovery. Transferred cases were followed up. Outcomes were unknown where children were removed from the hospital by caregivers prior to discharge or where it was inadvertently not documented. Audits were performed using a laboratory information system (LIS) for the public sector laboratories (80\% of healthcare in South Africa), where all cases satisfying the case definition not already reported to the surveillance system were added to the database.

\section{Definitions}

IPD cases were defined as all children with a known age of $\leq 2$ years with $S$. pneumoniae isolated from a normally sterile body site specimen, such as cerebrospinal fluid (CSF), blood, pleural and joint fluids, from January 2003 through December 2008, in South Africa. Individuals who presented within 21 days with a second episode of IPD were excluded.

Neonates were defined as infants $0-27$ days of age. We compared the characteristics of IPD in neonates with non-neonates ( 28 days to $\leq 2$ years of age), the age group associated with the highest incidence of IPD.

Early-onset disease (EOD) was defined where the specimen collection date was at age $<7$ days old, while late onset-disease (LOD) included all neonates with a specimen collection date at $\geq 7$ - 27 days of age [19]. 
Neonatal IPD in South Africa: 2003 - 2008

281 Specimen source was defined according to the specimen type positive for

282 pneumococcus as follows: CSF specimen, irrespective of any other specimen; blood

283 specimen irrespective of other specimen type (excluding CSF); and "other" including all

284 other normally sterile specimen types (excluding blood and CSF specimens).

285 Clinical syndromes, available from ES sites only, were defined as: meningitis, as

286 documented in clinical notes or if the IPD specimen was CSF; lower respiratory tract

287 infection, as documented in clinical notes, together with culture of an isolate from a

288 sterile site (including blood, pleural fluid); bacteremia without focus, where a focus was

289 not documented and the specimen was blood; "other" included all cases not included in

290 the definitions above.

291 "Pediatric" serotypes were defined as serotypes 6B, 9V, 14, 19F, and 23F. These have

292 been defined as a group of serotypes associated with increased antimicrobial resistance

293 and frequently isolated from children [20]. 
Neonatal IPD in South Africa: 2003 - 2008

294

295

296

297

298

299

300

301

302

303

304

305

306

307

308

309

310

311

312

313

314

315

316

\section{Incidence rates}

Incidence rates were calculated using the number of reported cases of IPD with known ages for each group as the numerator. The denominator for neonates was live births for each year, while that for the non-neonates was the number of one-month-old children subtracted from the mid-year population estimates for $\leq 2$-year-old children, for each year. The population estimates were extracted from Statistics South Africa [21]. Incidence was reported per 100000 population.

\section{Microbiology and serotyping}

Identification of the submitted pneumococcal isolates was confirmed at the NICD using standard microbiological techniques i.e. colony morphology, haemolysis and optochin susceptibility. Serotyping was performed with the Quellung reaction, using specific pneumococcal antisera (Statens Serum Institut, Copenhagen, Denmark). The serotypes included in PCV7 are 4, 6B, 9V, 14, 18C, 19F and 23F. PCV10 includes three additional serotypes: 1, 5, 7F, and PCV 13 an additional 3: 3, 6A, 19A [2].

All isolates were screened for penicillin resistance by disk diffusion testing using a $1 \mu \mathrm{g}$ oxacillin disk (Mast diagnostics, Merseyside, United Kingdom). Isolates testing nonsusceptible on screening had minimum inhibitory concentrations (MICs) determined by agar dilution or Etest ${ }^{\circledR}$ (AB-Biodisk, Solna, Sweden) for penicillin and ceftriaxone. Isolates were also tested against the following agents using the disk diffusion method: erythromycin, clindamycin, chloramphenicol, tetracycline, rifampicin, cotrimoxazole and ofloxacin - if non-susceptible, MICs were determined by Etest ${ }^{\circledR}$. Results were interpreted using Clinical and Laboratory Standards Institute (CLSI) 2013 guidelines [22]. Isolates were considered non-susceptible to penicillin at MICs $\geq 0.12 \mathrm{mg} / \mathrm{L}$ using 
Neonatal IPD in South Africa: 2003 - 2008

317 the parenteral penicillin meningitis breakpoints. For other antimicrobial agents, isolates

318 were defined as non-susceptible if they were intermediately or fully resistant to the

319 agent tested. Multidrug-resistance (MDR) was defined as non-susceptibility to at least

320 one agent in three or more different classes [23].

321 The recommendation for HIV testing at the time of the study was to perform a

322 qualitative DNA polymerase chain reaction for children $<18$ months of age and an

323 enzyme linked immunosorbent assay (ELISA) for children $\geq 18$ months of age [24], as

324 requested by the attending clinician.

\section{Statistical analysis}

326 Medians and interquartile ranges are presented for continuous variables and frequencies

327 are presented for categorical variables. Chi-square tests are used to compare groups. A

$328 p$ value (2-tailed) of $\leq 0.05$ was considered significant. Epi Info ${ }^{\mathrm{TM}}$ version 7.2.1.0 was

329 used to analyse the data. 
Neonatal IPD in South Africa: 2003 - 2008

330

Results

331

Demographics

332

There were 27630 reported IPD cases from January 2003 through December 2008, 26 277 (95\%) with known ages, of whom 25\% (6 583) were aged $\leq 2$ years, and $4.5 \%$ (294/6583) of these were neonates. Forty-two percent (2747/6583) of IPD cases were from ES sites, which included 31\% (92/294) neonates and 42\% (2655/6289) nonneonates $(p<0.01)$ (Table 1). In 2008, the national incidence of neonatal IPD was 5 per 100000 live births, 22-fold lower than the non-neonatal incidence of 110 per 100 000 population (Figure 1). The change in incidence was relatively stable from $2003-$ 2008 among both neonates and non-neonates $(p=0.05)$ except for a peak in neonatal incidence in 2007 (from 44 cases in 2006 to 70 cases in 2007) (Figure 1). There was no spatial or serotype clustering among these cases.

342 Although there was some variation in IPD incidence in the nine provinces, there was no statistically significant difference in provincial incidence when neonates were compared to non-neonates (data not shown).

The median age among neonates was six days (IQR 1.5 - 14) and among non-neonates was 231 days (IQR 127 - 386). There were more females among the neonates $(151 / 286,53 \%)$ than non-neonates $(2788 / 6113,46 \%)(\mathrm{p}=0.02)($ Table 1 , sex not documented in six neonates and 176 non-neonates). Of the $43(43 / 92,47 \%)$ neonates tested for HIV 44\% (19/43) were HIV infected while 67\% (1218/1831) of tested nonneonates $(1831 / 2655,69 \%)$ were HIV infected $(p<0.01)$ (Table 1). This difference was mainly because of a smaller proportion of EOD cases being HIV positive (4/16, $25 \%)$ than LOD cases $(15 / 27,56 \% ; p=0.1)$. 
Neonatal IPD in South Africa: 2003 - 2008

\section{Clinical features and case-fatality ratios (CFR)}

354 Clinical syndromes were available from 91/92 neonates and 2647/2655 non-neonates

355 from ES sites only. Neonates presented most frequently with meningitis $(36 / 91 ; 40 \%)$

356 compared to non-neonates $(898 / 2647 ; 34 \%, p=0.3)$ (Table 1). Non-neonates presented 357 most frequently with lower respiratory tract infections $(1318 / 2647 ; 50 \%)$ compared to 358 neonates $(28 / 91 ; 31 \%, p<0.01)$.

359 The outcomes were available for 90/92 neonates and 2627/2655 non-neonates from the 360 ES sites. The neonatal CFR was 31\% (28/90), while the non-neonatal CFR was 26\% $361(676 / 2627)(p=0.13)$ (Table 1). Cases with meningitis had the highest CFR among both neonates $(39 \% ; 14 / 36)$ and non-neonates $(37 \% ; 327 / 882)$ (Table 2).

\section{Serotype distribution}

364 Viable isolates were available for 76\% (5021/6583) of reported cases, 195 neonatal and 4826 non-neonatal isolates. There were 16 isolates that were non-typeable, 1 neonatal and 15 non-neonatal. PCV7 serotypes were responsible for 31\% (61/194) neonatal IPD and 59\% (2853/4811) non-neonatal IPD $(p<0.05)$ (Table 1). The PCV13 serotypes were responsible for $69 \%(134 / 194)$ of IPD in neonates and $84 \%$ in non-neonates (4 042/4 811) (Table 1). The proportion of PCV7 and PCV13 serotypes responsible for IPD in neonates was significantly lower than in non-neonates $(\mathrm{p}<0.01)$ (Table 1).

371 Forty-six percent (90/194) of neonatal IPD were accounted for by serotypes $5(\mathrm{n}=18)$, $1(n=17), 19 F(n=15), 3(n=14), 8(n=13)$ and $14(n=13)$. These serotypes were responsible for 33\% (1 572/4 811) of non-neonatal IPD serotypes $(p<0.01)$ (Figure 2).

374 Serotypes 1, 3 and 5 were more frequently isolated among neonates, 25\% (49/194), than among non-neonates, $5 \%(247 / 4$ 811) $(p<0.01)$ (Figure 2). The most common non- 
Neonatal IPD in South Africa: 2003 - 2008

376 neonatal serotypes were $14(\mathrm{n}=805), 6 \mathrm{~B}(\mathrm{n}=618), 6 \mathrm{~A}(\mathrm{n}=580), 23 \mathrm{~F}(\mathrm{n}=542), 19 \mathrm{~F}(\mathrm{n}$

$377=520)($ Figure 2$)$. The non-PCV13 serotypes 8, 12F and 13 accounted for $13 \%$

$378(25 / 194)$ of neonatal and 4\% (183/4811) of non-neonatal isolates (Figure 2).

\section{Antimicrobial susceptibility}

380 Antimicrobial susceptibility testing was performed on all 5021 viable isolates. Among neonates $76 \%(148 / 195)$ of isolates were susceptible to penicillin, compared to $50 \%$ (2424/4826) non-neonatal IPD isolates ( $\mathrm{p}<0.01)$ (Table 1). Most isolates in this study were susceptible to ceftriaxone, 99\% (194/195) and 98\% (4757/4826) among neonates and non-neonates, respectively (Table 1). Cotrimoxazole non-susceptibility was lower among neonates $(77 / 195,39 \%)$ than non-neonates $(3542 / 4826,73 \%)(p<0.01)$ (Table 1). Among all tested isolates, 27\%(1 361/5 021) were MDR, of which 15\% (30/195) were neonatal and 28\% (1 331/4 826) non-neonatal isolates $(p<0.01)$ (Table 1).

Six serotypes most commonly associated with non-susceptibility to penicillin were serotypes 14, 19F, 6B, 23F, 6A and 19A. These accounted for 89\% (42/47) and 91\% (2124/2402) of penicillin non-susceptible isolates among neonates and non-neonates, respectively (Figure 3). These six serotypes were also the most frequent among the MDR isolates. Serotype 14 was the predominant MDR serotype: 40\% (12/30) and 51\% (684/1 331) in neonates and non-neonates, respectively (Figure 3).

\section{Early-onset vs. late-onset disease}

Fifty-one percent (149/294) of neonates presented with EOD (Table 3). The median age for EOD was 0 days (IQR 0 - 2), with 66\% (99/149) presenting within 48 hours of birth. The median age for LOD was 14 days (IQR 10 - 22). The EOD patients were more likely to have blood specimen sources than LOD patients $(110 / 149,74 \%$ vs. 
Neonatal IPD in South Africa: 2003 - 2008

$39976 / 145,52 \%, p<0.01$, Table 3 ). LOD cases presented with meningitis more frequently 400 than EOD cases (LOD: 25/48; 52\% vs EOD: $11 / 43 ; 26 \%, p=0.01$ ) (Table 3 ). The 401 CFR was high in EOD and LOD, (14/44, 32\% and 14/48, 29\%, respectively).

402 Pneumonia in EOD $(6 / 14,43 \%)$ was associated with a higher CFR than in LOD, $(1 / 14$, $4037 \%)(p<0.03)$, while meningitis contributed substantially to the high CFR in both 404 groups, $(4 / 11,36 \%$ in EOD; $10 / 25,40 \%$ in LOD) $(p=0.7)$ (Table 4). 
Neonatal IPD in South Africa: 2003 - 2008

405

Discussion

406

407

408

409

410

411

412

413

414

415

416

417

418

419

420

421

422

423

424

425

426

427

428

In this study, conducted prior to introduction of PCV7 vaccination in South Africa, neonatal IPD accounted for an estimated $4,5 \%$ of IPD cases in children $\leq 2$ years of age. Almost $50 \%$ of these neonates presented within the first week of life, with meningitis and bacteremia without focus, being the predominant clinical presentations. PCV13 serotypes contributed to $69 \%$ of all neonatal cases. The most frequent neonatal serotypes 1, 3 and 5 accounted for $25 \%$ of neonatal and only $5 \%$ of non-neonatal IPD cases. Neonatal IPD was associated with a high CFR (31\%).

The national incidence of neonatal IPD, 5 per 100000 live births in South Africa in 2008, was lower than the estimated global incidence of 36 per 100000 live births in 2010 [4]. Billings et al reported an incidence of 16 per 100000 live births, prior to the introduction of PCV, in less-developed United Nations (UN) strata countries [4]. Our incidence is also much lower than the incidence reported in Chile, of 59 per 100000 population, and closer to that reported in the USA in 2006 (11 per 100000 live births), and in England and Wales in 2013 (13 per 100000 live births) prior to PCV, among $<90$ day old infants $[5,6,7]$. The incidence in this study is similar to that reported by Cutland et al, from a South African city, Soweto, where the incidence of neonatal sepsis due to the pneumococcus was reported as 8 per 100000 live births among neonates [25]. In the Sowetan study S. pneumoniae was noted to occur less frequently than other common causes of neonatal sepsis, such as Streptococcus agalactiae, Staphylococcus aureus, Streptococcus viridans and Escherichia coli [25]. Differences in incidence may be attributed to the higher threshold for taking blood culture specimens in neonatal units in South Africa, variation in surveillance methodologies and completeness in reporting $[4,7]$. The incidence we report may be an underestimate of true neonatal incidence as 
Neonatal IPD in South Africa: 2003 - 2008

429 infants with clinically evident, but microbiologically negative, sepsis would not have 430 been included in this study. In addition, the sensitivity of cultures among neonates is 431 low, attributable to inadequate sample volumes being submitted, as well as empiric 432 antimicrobials being commenced prior to cultures being taken [26, 27].

433 Among South African neonates, a large proportion of IPD cases, 51\%, presented with 434 EOD, similar to high-income countries like the USA and UK where 70\% (19/27) and $43577 \%$ (101/131), respectively, of neonatal IPD cases had EOD [5, 6]. This contrasts with 436 studies from Utah and Mexico, where only $11 \%$ (2/9) and 20\% (25/126) of neonatal cases, respectively, were EOD [28, 29]. The higher rates of EOD in South African neonates and those of the USA and England and Wales may be due to similar at risk populations, access to care and specimen-taking practices [4]. The variation between and within countries may be attributed to differences in small hospital-based studies, socioeconomic status, access to antenatal care and maternal and infant risk factors [28, 29].

In this study, 66\% (99/149) of the EOD neonates presented within the first 48 hours of life, similar to that reported by Ladhani et al in the UK, 67\% (84/101), who indicated that these infants were more likely to be premature [7]. Early-onset sepsis has been found to be associated with prematurity, maternal chorioamnionitis, or social factors influencing prenatal care [30]. We were unable to analyse for prematurity or other maternal factors as these data were not collected during the study period.

449 Although the association of IPD and HIV infection in children has been well 450 documented in South African children [31], this was not clear among neonates in this 451 study. The high rates among neonates with IPD, 44\%, may be because children that 
Neonatal IPD in South Africa: 2003 - 2008

were most ill or had signs of HIV were preferentially tested, or would have presented to a healthcare setting. In addition, HIV status data was only available for 15\% (43/294) of neonates as there was no policy for universal HIV testing at birth at the time of this study. While the lower HIV positivity rate among the EOD cases was responsible for the significantly lower HIV positivity rate among neonates, compared to non-neonates, this observation cannot be explored further as the numbers tested were very low.

We observed a female sex preponderance in this study. Two studies, in Mexico and Denmark, reported a male sex preponderance [29, 32], while others do not report a sex preponderance $[4,5]$ among neonates with IPD. A male sex predisposition to neonatal sepsis, particularly Gram-negative sepsis, has been attributed to x-linked immunoregulatory genes $[33,34]$. This predisposition may be specific to Gramnegative sepsis in neonates and therefore not consistently observed in neonatal IPD.

The predominant clinical presentation of neonates, bacteremia (42\%) among EOD cases, and meningitis (52\%) among LOD cases, in the South African setting was consistent with findings from England and Wales, and Mexico [7, 29]. Ladhani et al and Soto-Noguerón A et al reported bacteremia as the predominant presentation in the EOD cases and meningitis in the LOD cases [7, 29]. The more frequent diagnosis of bacteremia, and blood specimens in this study, among EOD cases may relate to an inability of the immature immune system in these very young babies to localize the infection [30, 35].

Although the CFR among neonates (31\%) was higher than that among non-neonates (26\%), this did not reach statistical significance. The neonatal CFR was also lower than those in other studies in England and Wales and the USA [7, 12]. This may be 
Neonatal IPD in South Africa: 2003 - 2008

475 attributed to an underestimation of the neonatal CFR, as infants who demised at home

476 would not have been included in this database. In addition, only 32\% (90/294) of

477 neonates with IPD had outcomes available for analysis. Meningitis, an established risk

478 factor for death in patients with IPD [7, 36], was associated with the highest CFR

479 among both neonates and non-neonates in this South African context. The CFR in

480 neonates with IPD in this study was higher than that of neonates with sepsis due to more

481 frequently encountered pathogens, such as Group B Streptococcus, 16,9\% [25] or

482 Escherichia coli, 6\% [37], in South Africa.

483 In this study the neonatal isolates were generally more susceptible to antimicrobials

484 tested (penicillin and ceftriaxone) than the non-neonatal isolates, as in the USA and

485 Mexico, prior to PCV7 [12, 29]. This is not unexpected as the neonatal serotypes,

486 unlike the pediatric serotypes, are usually not associated with antimicrobial resistance

$487[14,38,39]$.

Our findings of $31 \%$ PCV7 serotypes in neonatal IPD are consistent with pneumococcal vaccine studies from Mexico (34\%), and England and Wales (44\%), prior to PCV7 [29,

7]. The PCV13 serotype coverage among neonatal IPD isolates (69\%) was also comparable to those in Mexico (64\%), and England and Wales (67\%) [29, 7]. While $69 \%$ of neonatal IPD were due to PCV13 serotypes, this was significantly less than that observed in the non-neonatal IPD group (84\%). The common neonatal IPD serotypes 1 , 3 and 5 among South African neonates is consistent with other studies from the USA and Denmark $[12,32]$. These serotypes have been reported to occur more frequently among adults than children in the UK, Denmark, and South Africa [7, 32, 31]. This supports the widely accepted premise of neonatal IPD being acquired via horizontal spread from mother or adult caregiver [9]. 
Neonatal IPD in South Africa: 2003 - 2008

499 Herd protection has been reported to play a role in decreasing the incidence of IPD in 500 infants too young to be immunized, in studies post-PCV7 in England and Wales, USA 501 and in South Africa [6, 7, 40]. However, no change was observed in PCV7 IPD in 502 Mexico, in infants < 60 days old, after the introduction of PCV7, suggesting that herd 503 protection did not extend to the mothers of these infants [29]. The option of maternal 504 vaccination in such a setting, although reported to be safe, is currently not 505 recommended due to insufficient evidence that it will provide neonatal protection [16, 506 17].

507 This study has several limitations. First, the data were collected using a laboratory508 based surveillance system, where isolate submission is dependent on diligent local 509 laboratory and surveillance staff. Case ascertainment also suffers from differential 510 access to care and specimen-taking practices throughout the country. Only cases with 511 known ages were included. In addition, audits performed on the surveillance database 512 did not include private sector cases. Therefore, our estimates are an underestimation of 513 actual disease burden in children $\leq 2$ years old in South Africa. Second, as the study 514 was performed retrospectively we were unable to check for maternal factors, such as 515 premature labor, preterm rupture of membranes, maternal HIV infection, vaginal 516 colonization or maternal IPD. Neonatal data, especially relating to HIV infection and 517 outcomes, were also incomplete in our database. Third, susceptibility tests results were 518 interpreted using meningitis breakpoints irrespective of the clinical syndrome, therefore

519 the resistance rates appear higher in this study. This was appropriate as our study looked 520 at trends over time, and not treatment outcomes. Fourth, susceptibility testing for 521 ceftriaxone was revised from an agar dilution method to a CLSI-recommended broth 
Neonatal IPD in South Africa: 2003 - 2008

522 microdilution method, using TREK panels, in 2009 [22], as the agar dilution method

523 was found to underestimate beta-lactam resistance [41].

524 Since 2014, there has been renewed global interest in neonatal mortality, the primary

525 cause of which is neonatal sepsis [42]. The highest mortality rates have been reported

526 in sub-Saharan Africa [42]. In this setting, this study is well-timed in describing IPD in

527 this vulnerable group.

528 Our findings suggest that the pneumococcus, while not as common a cause of neonatal

529 sepsis as other agents like Group B Streptococcus or E.coli, is associated with a higher

530 CFR. Neonatal IPD in this country is found to be similar to neonatal IPD in other

531 countries in terms of clinical presentation, serotype distribution, antimicrobial

532 susceptibility, and CFRs. The findings in this study establish a baseline against which

533 to interpret changes that may occur in neonatal IPD since the implementation of PCV in

534 South Africa. 
Neonatal IPD in South Africa: 2003 - 2008

535

536

537

538

539

540

541

542

543

544

545

546

547

548

549

550

551

552

553

554

555

556

557

\section{References}

1. O'Brien KL, Wolfson LJ, Watt JP, Henkle E, et al. Burden of disease caused by Streptococcus pneumoniae in children younger than 5 years: global estimates. Lancet. 2009 Sep 12;374(9693):893-902. doi: 10.1016/S0140-6736(09)612046.

2. Pneumococcal vaccines WHO position paper 2012. Weekly epidemiological record/Health Section of the Secretariat of the League of Nations. 2012 Apr $6 ; 87(14): 129-44$.

3. Russell F, Sanderson C, Temple B, et al. Global review of the distribution of pneumococcal disease by age and region. 2011. http://www, who. int/immunization/sage/6_Russel_review _ age _ specific_epidemiology _ PCV _ schedules _ session_novl 1. pdf. Accessed March 2017.

4. Billings ME, Deloria-Knoll M, O'Brien KL. Global Burden of Neonatal Invasive Pneumococcal Disease: A Systematic Review and Meta-analysis. Pediatr Infect Dis J. 2016 Feb;35(2):172-9. doi: 10.1097/INF.0000000000000955.

5. Lagos R, Muñoz A, San Martin O et al. Age- and serotype-specific pediatric invasive pneumococcal disease: insights from systematic surveillance in Santiago, Chile, 1994-2007. J Infect Dis. 2008 Dec 15;198(12):1809-17. doi: $10.1086 / 593334$

6. Poehling KA, Talbot TR, Griffin MR, et al. Invasive pneumococcal disease among infants before and after introduction of pneumococcal conjugate vaccine. JAMA. 2006;295(14):1668-74. doi: 10.1001/jama.295.14.1668. 
Neonatal IPD in South Africa: 2003 - 2008

558

559

560

561

562

563

564

565

566

567

568

569

570

571

572

573

574

575

576

577

578

579

580

7. Ladhani SN, Andrews NJ, Waight $\mathrm{P}$, et al. Impact of the 7-Valent Pneumococcal Conjugate Vaccine on Invasive Pneumococcal Disease in Infants Younger Than 90 Days in England and Wale. Clinical Infectious Diseases, Volume 56, Issue 5, 1 March 2013, Pages 633-640,

\section{https://doi.org/10.1093/cid/cis934}

8. Barron P, Pillay Y, Doherty T, et al. Eliminating mother-to-child HIV transmission in South Africa. Bulletin of the World Health Organization. 2013;91(1):70-4. Epub 2013/02/12. doi: 10.2471/blt.12.106807.

9. Malhotra A, Hunt RW, Doherty RR. Streptococcus pneumoniae sepsis in the newborn. J Paediatr Child Health. 2012 Feb;48(2): E79-83. doi: 10.1111/j.1440-1754.2010.01929. x.

10. Rodriguez BF, Mascaraque LR, Fraile LR, et al. Streptococcus pneumoniae: the forgotten microorganism in neonatal sepsis. Fetal Pediatr Pathol. 2015 Jun;34(3):202-5. doi: 10.3109/15513815.2015.1033073.

11. Darmstadt GL, Zaidi AKM, Stoll BJ. Neonatal Infections: A Global Perspective. Infectious Diseases of the Fetus and Newborn. Seventh edition. Philadelphia: W.B. Saunders; 2011. p. 24-51.

12. Gomez M1, Alter S, Kumar ML, et al. Neonatal Streptococcus pneumoniae infection: case reports and review of the literature. Pediatr Infect Dis J. 1999 Nov;18(11):1014-8

13. Hoffman JA, Mason EO, Schutze GE, et al. Streptococcus pneumoniae infections in the neonate. Pediatrics. 2003;112(5):1095-102. Epub 2003/11/05. PubMed PMID: 14595052. 
14. Hausdorff WP, Feikin DR, Klugman KP. Epidemiological differences among pneumococcal serotypes. Lancet Infect Dis. 2005;5(2):83-93. Epub 2005/02/01. doi: 10.1016/s1473-3099(05)01280-6.

15. Kim TH, Johnstone J, Loeb M. Vaccine herd effect. Scandinavian Journal of Infectious Diseases. 2011;43(9):683-689. doi:10.3109/00365548.2011.582247.

16. Holmlund E, Nohynek H, Quiambao B, et al. Mother-infant vaccination with pneumococcal polysaccharide vaccine: persistence of maternal antibodies and responses of infants to vaccination. Vaccine. 2011;29(28):4565-75. Epub 2011/05/10. doi: 10.1016/j.vaccine.2011.04.068.

17. Chaithongwongwatthana S, Yamasmit W, Limpongsanurak S, et al. Pneumococcal vaccination during pregnancy for preventing infant infection. The Cochrane database of systematic reviews. 2015;1:CD004903. Epub 2015/01/24. doi: 10.1002/14651858.CD004903.pub4.

18. Huebner RE, Klugman KP, Matai U, et al. Laboratory surveillance for Haemophilus influenzae type B meningococcal, and pneumococcal disease. Haemophilus Surveillance Working Group. S Afr Med J. 1999;89(9):924-5. PubMed PMID: 10554623.

19. Pathirana J, Muñoz FM, Abbing-Karahagopian V, et al. Neonatal death: Case definition \& guidelines for data collection, analysis, and presentation of immunization safety data. Vaccine. 2016;34(49):6027-6037. doi: 10.1016/j.vaccine.2016.03.040. PMCID: PMC5139812

20. Crewe-Brown HH, Karstaedt AS, Saunders GL, et al. Streptococcus pneumoniae blood culture isolates from patients with and without human 
604

605

606

607

608

609

610

611

612

613

614

615

616

617

618

619

620

621

622

623

624

625

626

immunodeficiency virus infection: alterations in penicillin susceptibilities and in serogroups or serotypes. Clin Infect Dis 1997; 25:1165-72.

21. Mid-year population estimates, South Africa, 2010. Available from: http://www.statssa.gov.za/publications/P0302/P03033010.pdf. Accessed July 2016

22. Clinical and Laboratory Standards Institute. Performance standards for antimicrobial susceptibility testing. Twenty-third informational supplement. 2013; M100 - S23.

23. Magiorakos AP, Srinivasan A, Carey RB, et al. Multidrug-resistant, extensively drug-resistant, and pan drug-resistant bacteria: an international expert proposal for interim standard definitions for acquired resistance. Clin Microbiol Infect. 2012 Mar;18(3):268-81. doi: 10.1111/j.1469-0691.2011.03570.x

24. Singh E, Cohen C, Govender N, et al. A description of HIV testing strategies at 21 laboratories in South Africa. Commun Dis Surveill Bull. 2008; 6:16-17

25. Cutland CL. Epidemiology and Prevention of Sepsis in Young Infants and the Potential Impact of Maternal HIV Infection on Neonatal Sepsis. Wits Institutional Repository on DSpace, Electronic Theses and Dissertations. 2016. http://wiredspace.wits.ac.za/bitstream/handle/10539/22516/Cutland_PhD_final_ 280ct16.pdf. Accessed October 2017.

26. Lebea MM, Davies V. Evaluation of culture-proven neonatal sepsis at a tertiary care hospital in South Africa. South African Journal of Child Health 2017;11(4):170-173. Available at: http://www.sajch.org.za/index.php/SAJCH/article/view/1395 
Neonatal IPD in South Africa: 2003 - 2008

627

628

629

630

631

632

633

634

635

636

637

638

639

640

641

642

643

644

645

646

647

648

649

27. Schelonka RL, Chai MK, Yoder BA et al. Volume of blood required to detect common neonatal pathogens. J Pediatr. 1996 Aug;129(2):275-8. PMID: 8765627

28. Olarte L, Ampofo K, Stockmann C, et al. Invasive pneumococcal disease in infants younger than 90 days before and after introduction of PCV7. Pediatrics. 2013;132(1): e17-24. doi: 10.1542/peds.2012-3

29. Soto-Noguerón A, Carnalla-Barajas MN, Solorzano-Santos F, et al. Streptococcus pneumoniae as cause of infection in infants less than 60 days of age: serotypes and antimicrobial susceptibility. Int J Infect Dis. 2016; 42:69-73. Epub 2015/12/18. doi: 10.1016/j.ijid.2015.12.001.

30. Simonsen KA, Anderson-Berry AL, Delair SF, et al. Early-Onset Neonatal Sepsis. Clinical Microbiology Reviews. 2014;27(1):21-47. doi:10.1128/CMR.00031-13.

31. von Gottberg A, Cohen C, de Gouveia L, et al. Epidemiology of invasive pneumococcal disease in the pre-conjugate vaccine era: South Africa, 20032008. Vaccine. 2013;31(38):4200-8. Epub 2013/05/21. doi:

10.1016/j.vaccine.2013.04.077.

32. Kaltoft, M, Zeuthen, N and Konradsen, H. Epidemiology of invasive pneumococcal infections in children aged 0-6 years in Denmark: a 19-year nationwide surveillance study. 2000. Acta Pædiatrica, 89: 3-10. doi:10.1111/j.1651-2227.2000.tb00775.x

33. Nagwa GM, Begum S, El-Batanony MH, et al. Clinical and Bacteriological Profile of Neonatal Sepsis in King Khaleed Civilian Hospital, Tabuk, Kingdom 
Neonatal IPD in South Africa: 2003 - 2008

650

651

652

653

654

655

656

657

658

659

660

661

662

663

664

665

666

667

668

669

670

671

of Saudi Arabia. European Journal of Preventive Medicine. 2016; 4(1): 1-6. doi: 10.11648/j.ejpm.20160401.11

34. Karambin M, Zarkesh M. Enterobacter, the Most Common Pathogen of Neonatal Septicemia in Rasht, Iran. Iranian Journal of Pediatrics. 2011;21(1):83-87. PMID: 23056769

35. Bulkowstein S, Ben-Shimol S, Givon-Lavi N, et al. Comparison of early onset sepsis and community-acquired late onset sepsis in infants less than 3 months of age. BMC Pediatrics 2016: 16:82. https://doi.org/10.1186/s12887-016-0618-6

36. Nyasulu P, Cohen C, De Gouveia L, et al. Increased risk of death in Human Immunodeficiency Virus-infected children with Pneumococcal meningitis in South Africa, 2003-2005. PIDJ. 2011;30(12): 1075 - 1080. PubMed PMID: 21799459 DOI: 10.1097/INF.0b013e31822cca05.

37. Motara F, Ballot DE, Perovic O. Epidemiology of neonatal sepsis at Johannesburg Hospital. The Southern African Journal of Epidemiology and Infection 2005; 20 (3): 90-93.

https://doi.org/10.1080/10158782.2005.11441243

38. Hausdorff WP. The roles of pneumococcal serotypes 1 and 5 in paediatric invasive disease. Vaccine. 2007 Mar 22;25(13):2406-12. DOI:

10.1016/j.vaccine.2006.09.009

39. Von Mollendorf C, Cohen C, Tempia S, et al. Epidemiology of Serotype 1 Invasive Pneumococcal Disease, South Africa, 2003-2013. Emerging Infectious Diseases. 2016;22(2):261-270. doi:10.3201/eid2202. 150967. 
Neonatal IPD in South Africa: 2003 - 2008

672

673

674

675

676

677

678

679

680

681

682

683

684

685
40. von Gottberg A, de Gouveia L, Tempia S, et al. Effects of vaccination on invasive pneumococcal disease in South Africa. The N Engl J Med. 2014;371(20):1889-99. Epub 2014/11/12. doi: 0.1056/NEJMoa1401914.

41. von Mollendorf C, Cohen C, de Gouveia L, et al. Factors associated with ceftriaxone non-susceptibility of Streptococcus pneumoniae: analysis of South African national surveillance data, 2003 to 2010. Antimicrobial agents and chemotherapy. 2014;58(6):3293-305. Epub 2014/04/02. doi: 10.1128/aac.02580-13.

42. Hug L, Sharrow D, and You D, et al. Levels \& Trends in Child Mortality. Estimates Developed by the UN Inter-Agency Group for Child Mortality Estimation United (UN IGME). Report 2017. Available at http://www.who.int/maternal_child_adolescent/documents/levels_trends_child_ mortality_2017/en/ 
Neonatal IPD in South Africa: 2003 - 2008

Figures and Tables for manuscript 
Neonatal IPD in South Africa: 2003 - 2008

Table 1: Characteristics of invasive pneumococcal disease in children $\leq 2$ years of age in South Africa, $2003-2008$, by age group (neonates vs non-neonates)

\begin{tabular}{|c|c|c|c|c|c|}
\hline \multicolumn{2}{|c|}{ Characteristic } & \multicolumn{2}{|c|}{ Age group } & & \multirow{3}{*}{$\begin{array}{c}\text { Total } \\
\mathrm{N}=6583\end{array}$} \\
\hline & & \multirow{2}{*}{$\begin{array}{c}<28 \text { days } \\
\mathrm{N}=294\end{array}$} & \multicolumn{2}{|l|}{$\geq 28$ days $\leq 2$ years } & \\
\hline & & & $\mathrm{N}=6289$ & $p$ value & \\
\hline & & $\mathrm{n}(\%)$ & $\mathrm{n}(\%)$ & & $\mathrm{n}(\%)$ \\
\hline $\operatorname{Sex}^{\mathbf{a}}$ & Female & $151(53)$ & $2788(46)$ & 0.02 & $2939(46)$ \\
\hline \multirow[t]{3}{*}{ Specimen } & Cerebrospinal fluid & $106(36)$ & $2178(35)$ & 0.67 & $2284(35)$ \\
\hline & Blood & $186(63)$ & $3957(63)$ & 0.95 & $4143(63)$ \\
\hline & Other & $2(1)$ & $154(2)$ & & $156(2)$ \\
\hline $\begin{array}{l}\text { Enhanced surveillance sites } \\
(\mathrm{ES})^{\mathrm{b}}\end{array}$ & Yes & $92(31)$ & $2655(42)$ & $<0.01$ & $2747(42)$ \\
\hline \multirow[t]{3}{*}{ HIV status ${ }^{c}$} & Positive & $19(44)$ & $1218(67)$ & $<0.01$ & $1237(66)$ \\
\hline & Negative & $24(56)$ & $613(33)$ & & $637(34)$ \\
\hline & Tested & $43(47)$ & $1831(69)$ & $<0.01$ & $1874(68)$ \\
\hline \multirow[t]{4}{*}{ Clinical presentation $^{d}$} & Meningitis & $36(40)$ & $898(34)$ & 0.3 & $934(34)$ \\
\hline & Pneumonia & $28(31)$ & $1318(50)$ & $<0.01$ & $1346(49)$ \\
\hline & Bacteremia & $27(30)$ & $185(7)$ & $<0.01$ & $212(8)$ \\
\hline & Other $^{\mathrm{e}}$ & 0 & $246(9)$ & & $246(9)$ \\
\hline
\end{tabular}




\begin{tabular}{|c|c|c|c|c|c|}
\hline \multicolumn{2}{|c|}{ Characteristic } & \multicolumn{2}{|c|}{ Age group } & & \multirow[b]{2}{*}{ Total } \\
\hline & & $<28$ days & $\geq 28$ days $\leq 2$ yea & & \\
\hline & & $\mathrm{N}=294$ & $\mathrm{~N}=6289$ & $p$ value & $\mathrm{N}=6583$ \\
\hline & & $\mathrm{n}(\%)$ & $\mathrm{n}(\%)$ & & $\mathrm{n}(\%)$ \\
\hline \multirow[t]{3}{*}{ Antimicrobial susceptibility ${ }^{f}$} & Penicillin NS & $47(24)$ & $2405(50)$ & $<0.01$ & $2449(49)$ \\
\hline & Ceftriaxone NS & $1(1)$ & $69(1)$ & & $70(1)$ \\
\hline & Cotrimoxazole NS & $77(39)$ & $3542(73)$ & $<0.01$ & $3619(72)$ \\
\hline Multidrug-resistance & Yes & $30(15)$ & $1331(28)$ & $<0.01$ & $1361(27)$ \\
\hline \multirow[t]{2}{*}{ PCV serotypes } & PCV7 & $61(31)$ & $2835(59)$ & $<0.01$ & $2896(58)$ \\
\hline & PCV13 & $134(69)$ & $4042(84)$ & $<0.01$ & $4176(84)$ \\
\hline Outcomes $^{9}$ & Demised & $28(31)$ & $676(26)$ & 0.13 & 704 (26) \\
\hline
\end{tabular}

Footnotes: Abbreviations - HIV = Human immunodeficiency virus, NS = non-susceptible

${ }^{a}$ There were 8 neonates and 176 non-neonates with sex unknown. ${ }^{\mathrm{b}}$ There were 92 neonates and 2655 non-neonates from ES sites. ${ }^{\mathrm{c}} \mathrm{HIV}$ test results (ES sites only), were not available for 49/92 neonates and 824/2655 non-neonates. ${ }^{\mathrm{d}}$ The denominator for diagnosis included all children from ES sites, and excluded those where no diagnosis was recorded: 9 neonates and 8 non-neonates, therefore 91 neonates and 2647 non-neonates were included in this analysis. The clinical diagnosis recorded in the category "other" included gastroenteritis $(\mathrm{n}=194)$, soft tissue, bone, and joint infections $(\mathrm{n}=42)$, other diagnoses $(\mathrm{n}=10)$. ${ }^{\mathrm{f}}$ There were 5021 viable isolates with susceptibility data available, $\mathrm{N}=195$ neonates and $\mathrm{N}=4826$ non-neonates. ${ }^{\mathrm{g}}$ Outcomes were available for 90/92 neonates and 2627/2655 non-neonates (ES sites only). 
Table 2: Case-fatality ratios (CFR) in children $\leq 2$ years of age with invasive pneumococcal disease in South Africa, by age group (neonates vs. non-neonates) and clinical presentation, 2003 - 2008

\begin{tabular}{lccc|c}
\hline Clinical syndrome & \multicolumn{3}{c|}{ Age group } & \\
& $<28$ days & $\geq 28$ days $\leq 2$ years & $p$-value & Total \\
& CFR $(\mathrm{n} / \mathrm{N})$ & CFR $(\mathrm{n} / \mathrm{N})$ & & CFR(n/N) \\
\hline Meningitis & $39(14 / 36)$ & $37(327 / 882)$ & 0.8 & $37(341 / 918)$ \\
Pneumonia & $25(7 / 28)$ & $19(245 / 1310)$ & 0.4 & $19(252 / 1338)$ \\
Bacteremia & $17(6 / 25)$ & $21(39 / 182)$ & 0.7 & $22(45 / 207)$ \\
\hline
\end{tabular}

Footnote: Abbreviations $-\mathrm{CFR}=$ case fatality ratio.

The clinical category of "other" $(\mathrm{n}=246)$ was excluded from the analysis of case-fatality ratios by clinical syndrome, as there were no neonatal cases in this category. The cases without a clinical diagnosis, 1 neonate and 8 non-neonates, were excluded, as were the 2 neonates and 28 non-neonates whose outcomes were not available. Final denominators used: Neonates = 89; Non-neonates $=2374$. 
Neonatal IPD in South Africa: 2003 - 2008

Table 3: Characteristics of neonates with invasive pneumococcal disease in South Africa: 2003 - 2008, by age of presentation: early versus late-onset disease

\begin{tabular}{|c|c|c|c|c|}
\hline & & Early-onset disease $(0-6$ days old $)$ & Late-onset disease $(\geq 7<28$ days old $)$ & \\
\hline & & $\mathrm{N}=149$ & $\mathrm{~N}=145$ & $p$ value \\
\hline & & $\mathrm{n}(\%)$ & $\mathrm{n}(\%)$ & \\
\hline $\operatorname{Sex}^{\mathrm{a}}$ & Female & $73(51)$ & $78(55)$ & 0.55 \\
\hline \multirow[t]{3}{*}{ Specimen } & Cerebrospinal fluid & $39(26)$ & $67(46)$ & $<0.01$ \\
\hline & Blood & $110(74)$ & $76(52)$ & $<0.01$ \\
\hline & Other & 0 & $2(1)$ & \\
\hline ES sites & Yes & $44(48)$ & $48(52)$ & 0.60 \\
\hline \multirow[t]{3}{*}{ HIV status ${ }^{b}$} & Positive & $4(25)$ & $15(56)$ & 0.1 \\
\hline & Negative & $12(75)$ & $12(44)$ & \\
\hline & Tested & $16(36)$ & $27(56)$ & 0.1 \\
\hline \multirow[t]{3}{*}{ Clinical presentation $^{c}$} & Meningitis & $11(26)$ & $25(52)$ & 0.01 \\
\hline & Pneumonia & $14(33)$ & $14(29)$ & 0.9 \\
\hline & Bacteremia & $18(42)$ & $9(19)$ & 0.02 \\
\hline Outcomes $^{\mathrm{d}}$ & Demised & $14 / 42(33)$ & $14 / 48(29)$ & 0.70 \\
\hline
\end{tabular}


Neonatal IPD in South Africa: 2003 - 2008

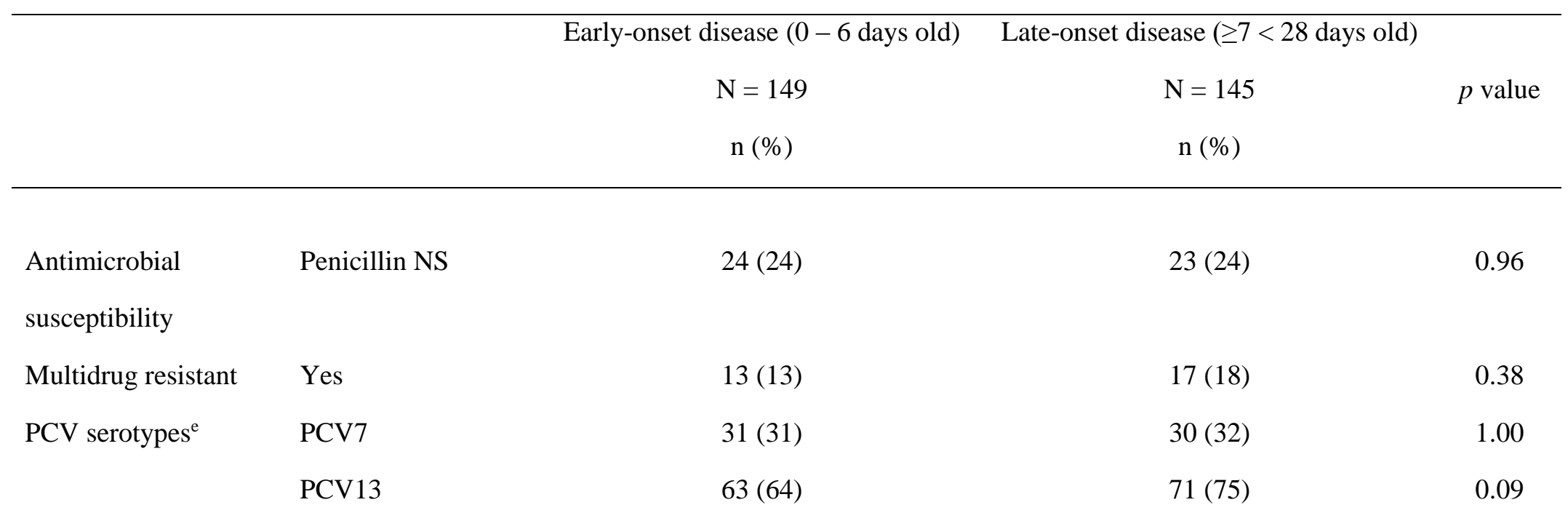

Footnotes: Abbreviations $-\mathrm{ES}=$ enhanced surveillance sites, $\mathrm{NS}=$ non-susceptible, $\mathrm{EOD}=$ early-onset disease, $\mathrm{LOD}=$ late-onset disease, $\mathrm{PCV}=$ pneumococcal conjugate vaccine.

${ }^{a}$ Sex - there were 6 EOD and 2 LOD cases where the sex was unknown. ${ }^{b}$ HIV status was not known in 28 EOD and 21 LOD cases from ES sites. There were 91 neonates, 43 with EOD and 48 with LOD, with known clinical diagnoses. ${ }^{\mathrm{d}}$ Two cases from the ES sites did not have a documented outcome. ${ }^{\mathrm{e}}$ There was $1 / 195$ viable isolates that was non-typeable among the LOD cases. 
Table 4: Case-fatality ratios (CFR) in children < 28 days of age with invasive pneumococcal disease in South Africa, by age of presentation (early vs. late-onset disease) and clinical presentation, 2003 - 2008

\begin{tabular}{|c|c|c|c|}
\hline & Early-onset disease & Late-onset disease & \\
\hline & $<7$ days & $\geq 7$ days $-<28$ days & $p$ value \\
\hline & CFR (n/N) & CFR (n/N) & \\
\hline Meningitis & $36(4 / 11)$ & $40(10 / 25)$ & 0.7 \\
\hline Pneumonia & $43(6 / 14)$ & $7(1 / 14)$ & 0.03 \\
\hline Bacteremia & $19(3 / 16)$ & $33(3 / 9)$ & 0.5 \\
\hline
\end{tabular}

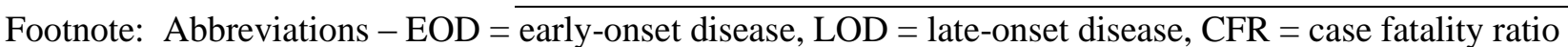

Two of the 92 neonates from ES sites did not have an outcome documented. These 2, as well as the one neonate with an unknown clinical diagnosis, were excluded from the further analysis of CFR by clinical syndrome. 


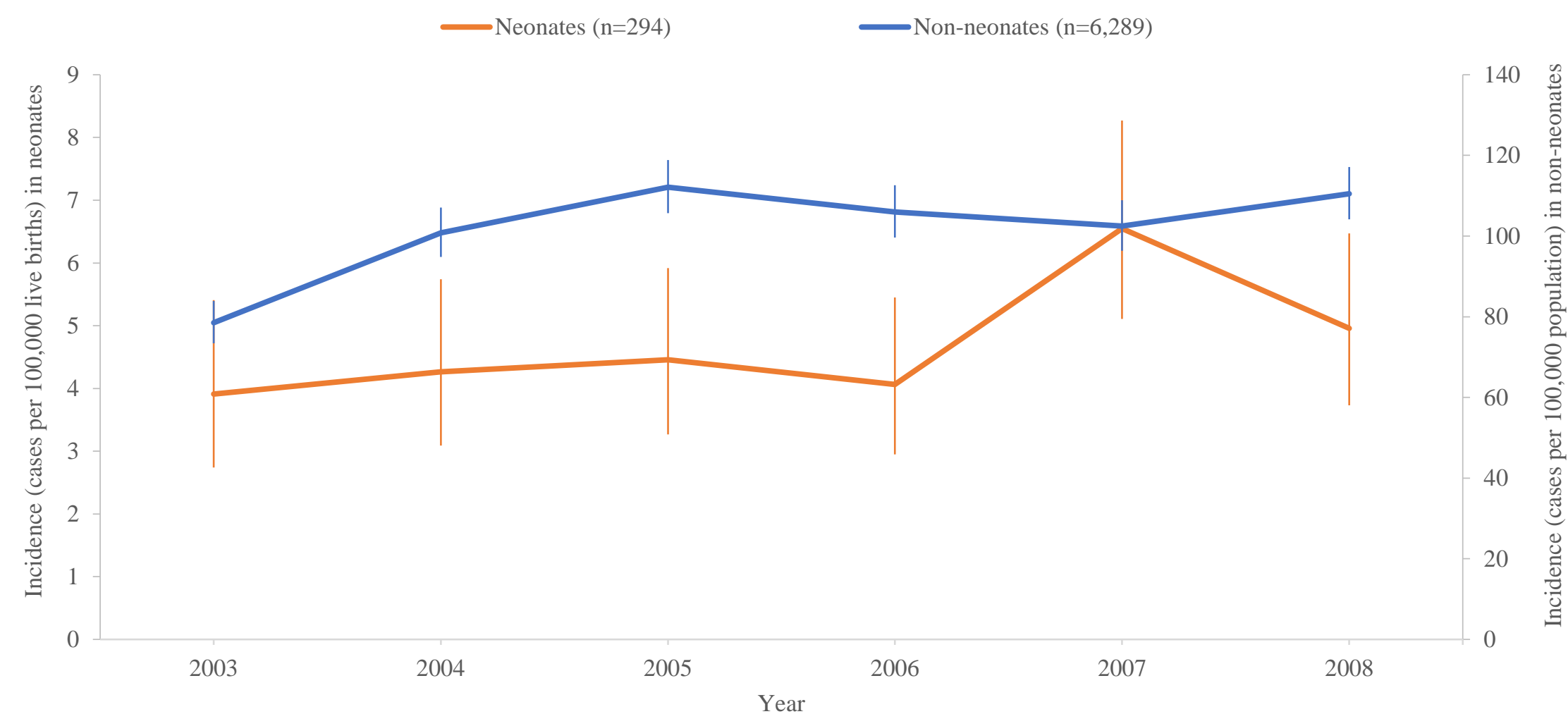

Figure 1: Incidence rates* (showing 95\% confidence intervals) of invasive pneumococcal disease in neonates and non-neonates " $(\geq$ 28 days $-\leq 2$ years), by year, South Africa, 2003-2008 $(n=6,583)$

* Incidence rates were calculated based on population denominators provided by Statistics South Africa, and are expressed as cases per 100,000 population 


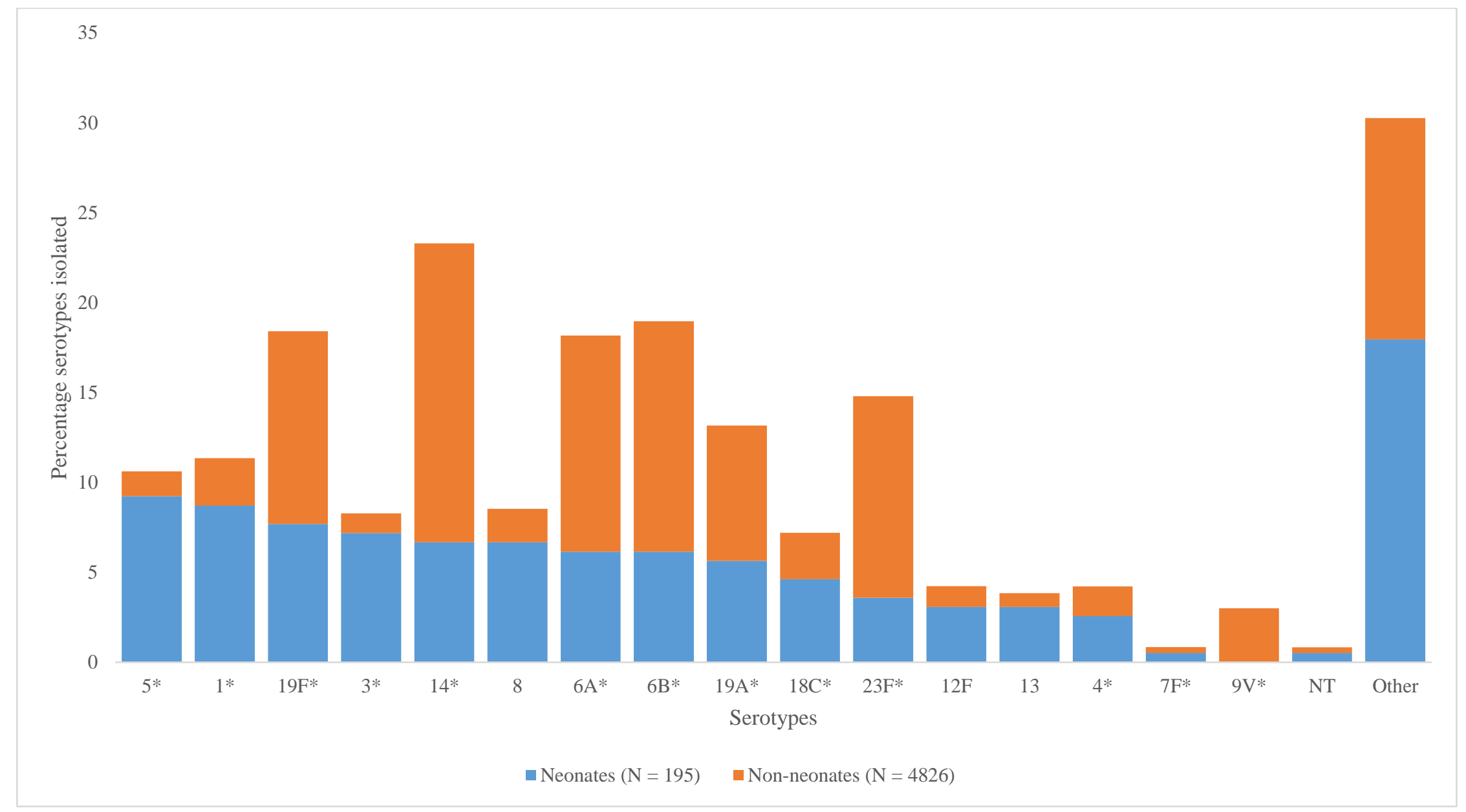

Figure 2: Most common serotypes among children $\leq 2$ years of age, with invasive pneumococcal disease in South Africa: $2003-$ 2008 by age group (neonates versus non-neonates) $(*=$ PCV13 serotypes) 


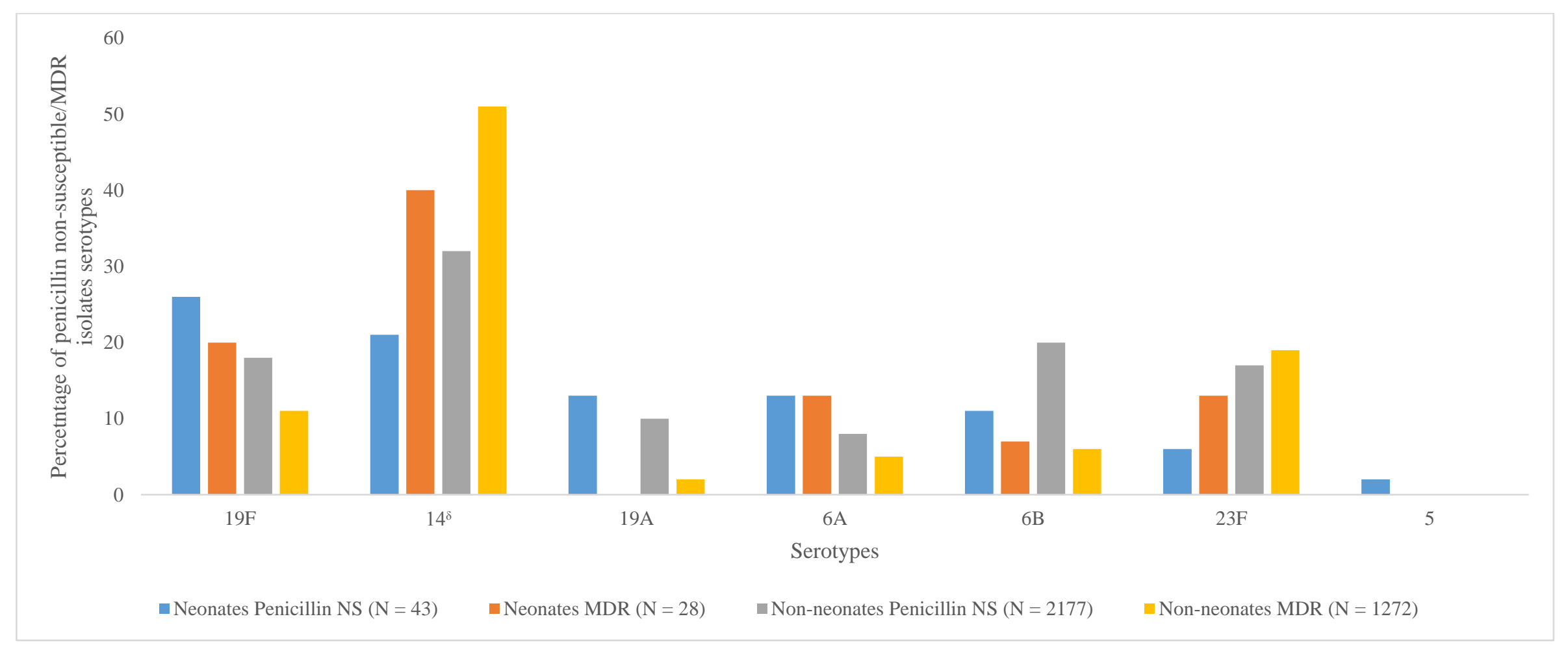

Figure 3: Serotype distribution of penicillin non-susceptible and multi-drug resistant(MDR) invasive pneumococcal disease isolates in children $\leq 2$ years of age in South Africa, 2003 -2008, by age group

Footnote: Abbreviations: NS = non-susceptible; MDR = multi-drug resistant. These 7 serotypes accounted for 91\% (43/47) of the penicillin nonsusceptible neonatal isolates. Serotype $19 \mathrm{~F}$ was the only serotype where the $\%$ neonatal penicillin non-susceptible isolates exceeded that of the nonneonates $(p=0.03) .{ }^{\delta}$ Serotype 14 was associated with the most multi-drug resistance among both neonates and non-neonates. 


\section{CHAPTER 3: REFERENCES}

\section{References for Literature review (Chapter 1)}

1. You D, Hug L, Ejdemyr S, et al. Levels \& Trends in Child Mortality. Estimates Developed by the UN Inter-Agency Group for Child Mortality Estimation United (UN IGME). Report 2015.

2. O'Brien KL, Wolfson LJ, Watt JP, Henkle E, et al. Burden of disease caused by Streptococcus pneumoniae in children younger than 5 years: global estimates. Lancet. 2009 Sep 12;374(9693):893-902. doi: 10.1016/S0140-6736(09)61204-6.

3. Rudan I, O'Brien KL, Nair H, et al. Epidemiology and etiology of childhood pneumonia in 2010: estimates of incidence, severe morbidity, mortality, underlying risk factors and causative pathogens for 192 countries. J Glob Health. 2013 Jun;3(1):010401. doi: 10.7189/jogh.03.010401.

4. Pneumococcal vaccines WHO position paper 2012. Weekly epidemiological record/Health Section of the Secretariat of the League of Nations. 2012 Apr 6;87(14):129-44. PMID: 24340399

5. Winther TN, Kristensen TD, Kaltoft MS, et al. Invasive pneumococcal disease in Danish children, 1996-2007, prior to the introduction of heptavalent pneumococcal conjugate vaccine. Acta Paediatr. 2009 Feb;98(2):328-31. doi: 10.1111/j.1651-2227.2008.01080. x.

6. von Gottberg A, Cohen C, de Gouveia L, et al. Epidemiology of invasive pneumococcal disease in the pre-conjugate vaccine era: South Africa, 20032008. Vaccine. 2013 Aug 28;31(38):4200-8. doi: 0.1016/j.vaccine.2013.04.077. 
7. Meiring S, Cohen C, Quan V, et al. HIV Infection and the Epidemiology of Invasive Pneumococcal Disease (IPD) in South African Adults and Older Children Prior to the Introduction of a Pneumococcal Conjugate Vaccine (PCV). PLoS One. 2016 Feb 10;11(2): e0149104. doi: 10.1371/journal.pone.0149104.

8. Gomez M1, Alter S, Kumar ML, et al. Neonatal Streptococcus pneumoniae infection: case reports and review of the literature. Pediatr Infect Dis J. 1999 Nov;18(11):1014-8

9. Hoffman JA, Mason EO, Schutze GE, et al. Streptococcus pneumoniae infections in the neonate. Pediatrics. 2003;112(5):1095-102. Epub 2003/11/05. PubMed PMID: 14595052.

10. Billings ME, Deloria-Knoll M, O'Brien KL. Global Burden of Neonatal Invasive Pneumococcal Disease: A Systematic Review and Meta-analysis. Pediatr Infect Dis J. 2016 Feb;35(2):172-9. doi: 10.1097/INF.0000000000000955.

11. Darmstadt GL, Zaidi AKM, Stoll BJ. Neonatal Infections: A Global Perspective. Infectious Diseases of the Fetus and Newborn. Seventh edition. Philadelphia: W.B. Saunders; 2011. p. 24-51.

12. Malhotra A, Hunt RW, Doherty RR. Streptococcus pneumoniae sepsis in the newborn. J Paediatr Child Health. 2012 Feb;48(2): E79-83. doi: 10.1111/j.14401754.2010.01929. $\mathrm{x}$.

13. Rodriguez BF, Mascaraque LR, Fraile LR, et al. Streptococcus pneumoniae: the forgotten microorganism in neonatal sepsis. Fetal Pediatr Pathol. 2015 Jun;34(3):202-5. doi: 10.3109/15513815.2015.1033073. 
14. Geelen SPM, Gerards L, and Fleer A. Pneumococcal septicemia in the newborn. A report on seven cases and a review of the literature. J Perinat Med. $1990 ; 18(2): 125-9$.

15. Soto-Noguerón A, Carnalla-Barajas MN, Solórzano-Santos F, et al. Streptococcus pneumoniae as cause of infection in infants less than 60 days of age: serotypes and antimicrobial susceptibility. Int J Infect Dis. 2016 Jan; 42:6973. doi: 10.1016/j.ijid.2015.12.001.

16. Westh H, Lillian S, Bent K. Streptococcus pneumoniae Infections of the Female Genital Tract and in the Newborn Child. Reviews of Infectious Diseases. $1990 ; 12(3): 416-22$

17. von Mollendorf C, von Gottberg A, Tempia S, et al. Increased risk for and mortality from invasive pneumococcal disease in HIV-exposed but uninfected infants aged < 1 year in South Africa, 2009-2013. Clin Infect Dis. 2015 May 1;60(9):1346-56. doi: 10.1093/cid/civ059.

18. Geno KA, Saad JS, Nahm MH. Discovery of Novel Pneumococcal Serotype 35D, a Natural WciG-Deficient Variant of Serotype 35B. J Clin Microbiol. 2017 May;55(5):1416-1425. doi: 10.1128/JCM.00054-17.

19. Hausdorff WP, Feikin DR, Klugman KP. Epidemiological differences among pneumococcal serotypes. Lancet Infect Dis. 2005;5(2):83-93. Epub 2005/02/01. doi: 10.1016/s1473-3099(05)01280-6.

20. Kaltoft, M., Zeuthen, N. and Konradsen, H. Epidemiology of invasive pneumococcal infections in children aged 0-6 years in Denmark: a 19-year nationwide surveillance study. 2000. Acta Pædiatrica, 89: 3-10. doi:10.1111/j.1651-2227.2000.tb00775.x 
21. Wang SA, Mantel CF, Gacic-Dobo M, et al. Progress in Introduction of Pneumococcal Conjugate Vaccine — Worldwide, 2000-2012. MMWR Morbidity and Mortality Weekly Report. 2013;62(16):308-311.

22. Ladhani SN, Andrews NJ, Waight P, et al. Impact of the 7-Valent Pneumococcal Conjugate Vaccine on Invasive Pneumococcal Disease in Infants Younger Than 90 Days in England and Wale. Clinical Infectious Diseases, Volume 56, Issue 5, 1 March 2013, Pages 633-640, https://doi.org/10.1093/cid/cis934

23. Kim TH, Johnstone J, Loeb M. Vaccine herd effect. Scandinavian Journal of Infectious Diseases. 2011;43(9):683-689. doi:10.3109/00365548.2011.582247.

24. Lopes CC, Berezin EN, Scheffer D, et al. Pneumococcal nasopharyngeal carriage in infants of mothers immunized with $23 \mathrm{~V}$ non-conjugate pneumococcal polysaccharide vaccine. J Trop Pediatr. 2012 Oct;58(5):348-52. doi: $10.1093 /$ tropej/fmr107.

25. Berezin EN, Lopes CC, Cardoso MRA. Maternal Immunization with Pneumococcal Polysaccharide Vaccine: Persistence of Maternal Antibodies in Infants. J Trop Pediatr. 2017 Apr 1;63(2):118-123. doi: 10.1093/tropej/fmw060.

26. Holmlund E, Nohynek H, Quiambao B, et al. Mother-infant vaccination with pneumococcal polysaccharide vaccine: persistence of maternal antibodies and responses of infants to vaccination. Vaccine. 2011;29(28):4565-75. Epub 2011/05/10. doi: 10.1016/j.vaccine.2011.04.068.

27. Chaithongwongwatthana S, Yamasmit W, Limpongsanurak S, et al. Pneumococcal vaccination during pregnancy for preventing infant infection. The 
Cochrane database of systematic reviews. 2015;1:CD004903. Epub 2015/01/24. doi: 10.1002/14651858.CD004903.pub4.

28. Hansman D, Glasgow H, Sturt J, et al. Increased resistance to penicillin of pneumococci isolated from man. N Engl J Med. 1971 Jan 28;284(4):175-7. DOI: 10.1056/NEJM197101282840403

29. Tomasz A. Antibiotic resistance in Streptococcus pneumoniae. Clinical Infectious Diseases 1997; 24(Suppl 1): S85-8

30. Appelbaum PC, Bhamjee A, Scragg JN, et al. Streptococcus pneumoniae resistant to penicillin and chloramphenicol. Lancet. 1977 Nov 12;2(8046):9957.

31. Hackel M, Lascols C, Bouchillon S, et al. Serotype prevalence and antibiotic resistance in Streptococcus pneumoniae clinical isolates among global populations. Vaccine. 2013 Oct 1;31(42):4881-7. doi: 10.1016/j.vaccine.2013.07.054.Vaccine. 2013 Oct 1;31(42):4881-7.

32. Magiorakos AP, Srinivasan A, Carey RB, et al. Multidrug-resistant, extensively drug-resistant, and pan drug-resistant bacteria: an international expert proposal for interim standard definitions for acquired resistance. Clin Microbiol Infect. 2012 Mar;18(3):268-81. doi: 10.1111/j.1469-0691.2011.03570.x

33. Crowther-Gibson P, Cohen C, Klugman KP, et al. Risk factors for multidrugresistant invasive pneumococcal disease in South Africa, a setting with high HIV prevalence, in the prevaccine era from 2003 to 2008. Antimicrob Agents Chemother. 2012 Oct;56(10):5088-95. DOI: 10.1128/AAC.06463-11 
34. Fuchsa A, Bielickia,Jb, Mathurb S et al. Antibiotic Use for Sepsis in Neonates and Children: 2016 Evidence Update. World Health Organization, WHO Reviews 2016.

35. Slotved HC, Dalby T, Hoffmann S. Invasive pneumococcal isolates from Danish infants (0 - 90 Days) during the years 1943 to 2013. PLoS One. 2014 Aug 26;9(8): e106180. doi: 10.1371/journal.pone.0106180.

36. Poehling KA, Talbot TR, Griffin MR, et al. Invasive pneumococcal disease among infants before and after introduction of pneumococcal conjugate vaccine. JAMA. 2006;295(14):1668-74. doi: 10.1001/jama.295.14.1668.

37. Lagos R, Muñoz A, San Martin O et al. Age- and serotype-specific pediatric invasive pneumococcal disease: insights from systematic surveillance in Santiago, Chile, 1994-2007. J Infect Dis. 2008 Dec 15;198(12):1809-17. doi: $10.1086 / 593334$

38. Baş AY, Demirel N, Aydin M, et al. Pneumococcal meningitis in the newborn period in a prevaccination era: a 10-year experience at a tertiary intensive care unit. Turk J Pediatr. 2011 Mar-Apr;53(2):142-8.

39. Olarte L, Ampofo K, Stockmann C, et al. Invasive pneumococcal disease in infants younger than 90 days before and after introduction of PCV7. Pediatrics. 2013 Jul;132(1): e17-24. doi: 10.1542/peds.2012-3900

40. Mount V, Burton C, Jackson C, et al. Neonatal invasive pneumococcal disease: New Zealand experience in the era of pneumococcal vaccination. Aust N Z J Obstet Gynaecol. 2017 Jun;57(3):280-285. doi: 10.1111/ajo.12512. 
Neonatal IPD in South Africa: 2003 - 2008

\section{CHAPTER 4: APPENDICES}

1. Approval letters from post-graduate office $(\mathrm{UKZN})$ and ethics committee (UKZN)

2. Valid ethics certificate

3. Case report form - NICD 
Neonatal IPD in South Africa: 2003 - 2008

1. Approval letters from post-graduate office (UKZN) and ethics committee (UKZN) 
Neonatal IPD in South Africa: 2003 - 2008

2 February 2010

UNIVERSITY OF

Professor Y Coovadia

Department of Medical Microbiology

NRMSM

UKZN

Dear Professor Coovadia

PROTOCOL: Invasive Pneumococcal Disease in Neonates in South Africa: 2000 - 2007. K Moodley 913482641 , MMed.

The Postgraduate Education Committee ratified the approval of the abovementioned study on 2 February 2010.

Please note:

- The Postgraduate Education Committee must review any changes made to this study.

- The study may not begin without the approval of the Biomedical Research Ethics Committee.

May I take this opportunity to wish the student every success with the study.

Yours sincerely

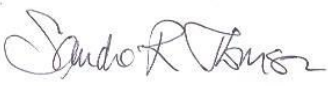

Professor SR Thomson

Dean's Assistant: MMed Programme

Postgraduate Education Committee

CC. Dr K Moodley

Ms D Ramnarain

Biomedical Research Ethics Committee

Westville Campus

Postgraduate Education Administration,

Medical School Campus

Postal Address: Private Bag 7, Congella, 4013, South Africa

Telephone: +27 (0) 312604327

Facsimile: $+27(0) 312604401$

Emall: heslopd@ukzn.ac.zo

Website: www.ukzn.ac.zo 
Neonatal IPD in South Africa: 2003 - 2008

\title{
27 August 2010
}

\author{
Dr. Krishnee Moodley \\ Department of Medical Microbiology, $4^{\text {th }}$ Floor \\ Inkosi Albert Luthuli Central Hospital \\ 800 Bellair Road, \\ Cato Manor \\ Durban
}

PROTOCOL: Invasive Pneumococcal Disease in Neonates in South Africa:2000-

2007. REF: BE012/010.

\section{EXPEDITED APPLICATION}

A sub-committee of the Biomedical Research Ethics Committee has considered and noted your application dated 12 January 2010.

The study was provisionally approved pending appropriate responses to queries raised. Your responses dated 12 July 2010 to queries raised on 01 March 2010 have been noted by a sub-committee of the Biomedical Research Ethics Committee. The conditions have now been met and the study is given full ethics approval and may begin as from 27 August 2010.

This approval is valid for one year from 27 August 2010. To ensure uninterrupted approval of this study beyond the approval expiry date, an application for recertification must be submitted to BREC on the appropriate BREC form 2.3 months before the expiry date.

Any amendments to this study, unless urgently required to ensure safety of participants, must be approved by BREC prior to implementation.

Your acceptance of this approval denotes your compliance with South African National Research Ethics Guidelines (2004), South African National Good Clinical Practice Guidelines (2006) (if applicable) and with UKZN BREC ethics requirements as contained in the UKZN BREC Terms of Reference and Standard Operating Procedures, all available at http://research.ukzn.ac.za/ResearchEthics11415.aspx. 
Neonatal IPD in South Africa: 2003 - 2008

BREC is registered with the South African National Health Research Ethics Council (REC-290408-009). BREC has US Office for Human Research Protections (OHRP) Federal-wide Assurance (FWA 678).

The sub-committee's decision will be RATIFIED at a full sitting of the Biomedical Research Ethics Committee meeting to be held on 12 October 2010.

We wish you well with this study. We would appreciate receiving copies of all publications arising out of this study.

Yours sincerely

Professor D.R Wassenaar

Chair: Biomedical Research Ethics Committee 
Neonatal IPD in South Africa: 2003 - 2008

2. Ethics certificate

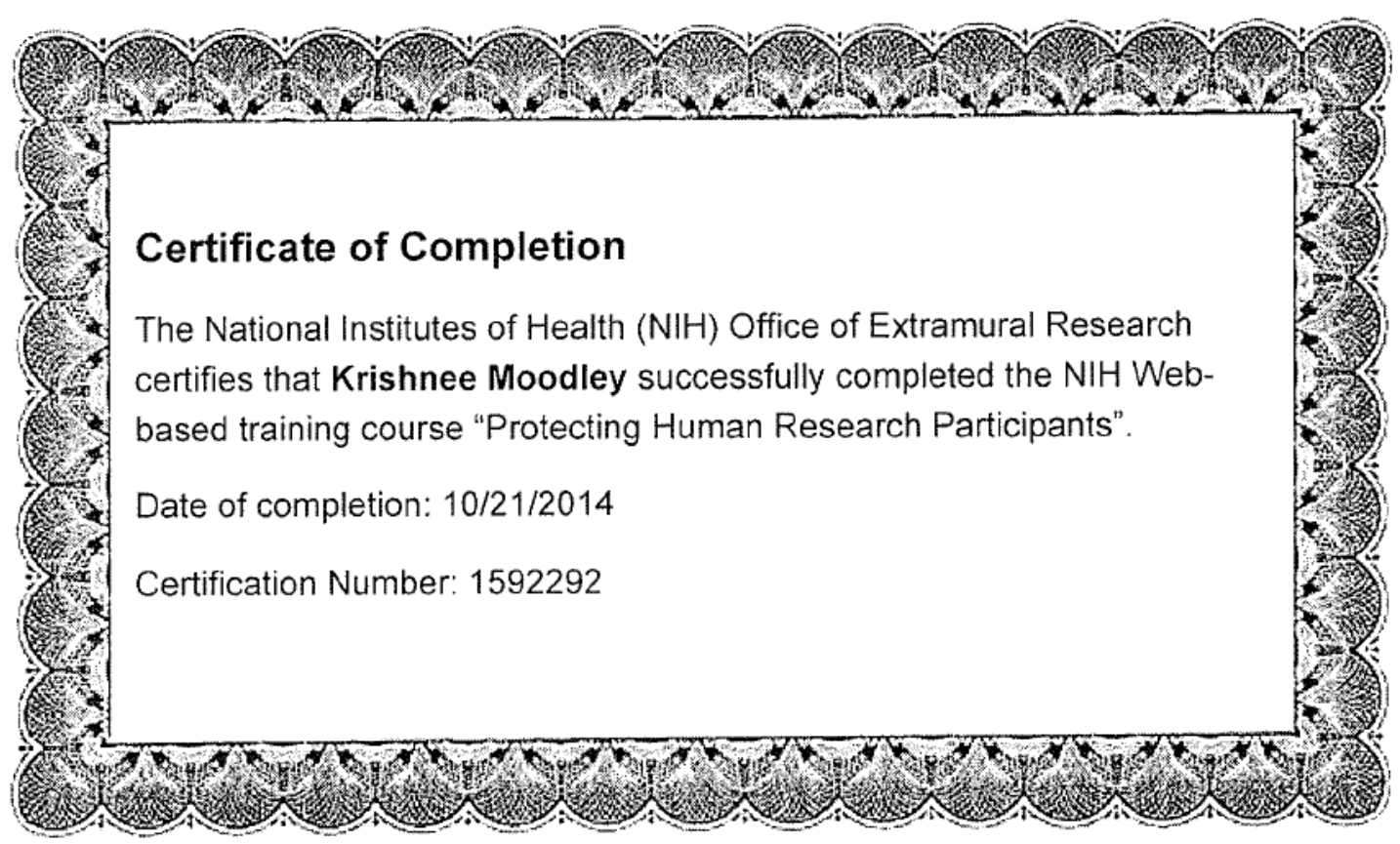


Neonatal IPD in South Africa: 2003 - 2008

\section{Case report form (CRF)}

These were the forms utilized by the surveillance officers, from NICD, to collect additional data from patients presenting at one of the enhanced surveillance sites. The additional data included clinical diagnosis, outcomes, HIV status. 
GERMS-SA: National Laboratory-based Surveillance for Enteric, Respiratory and Meningeal

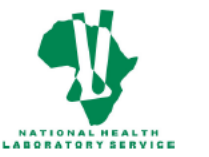

Bacterial and Fungal Diseases in South Africa

Protocol Version 1.4 (January 2009)

Clinical Case Report Form

National Microbiology Surveillance Unit (NMSU)

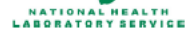

TEL: 0113866234 OR $0115550353 \quad$ FAX: 0113866077

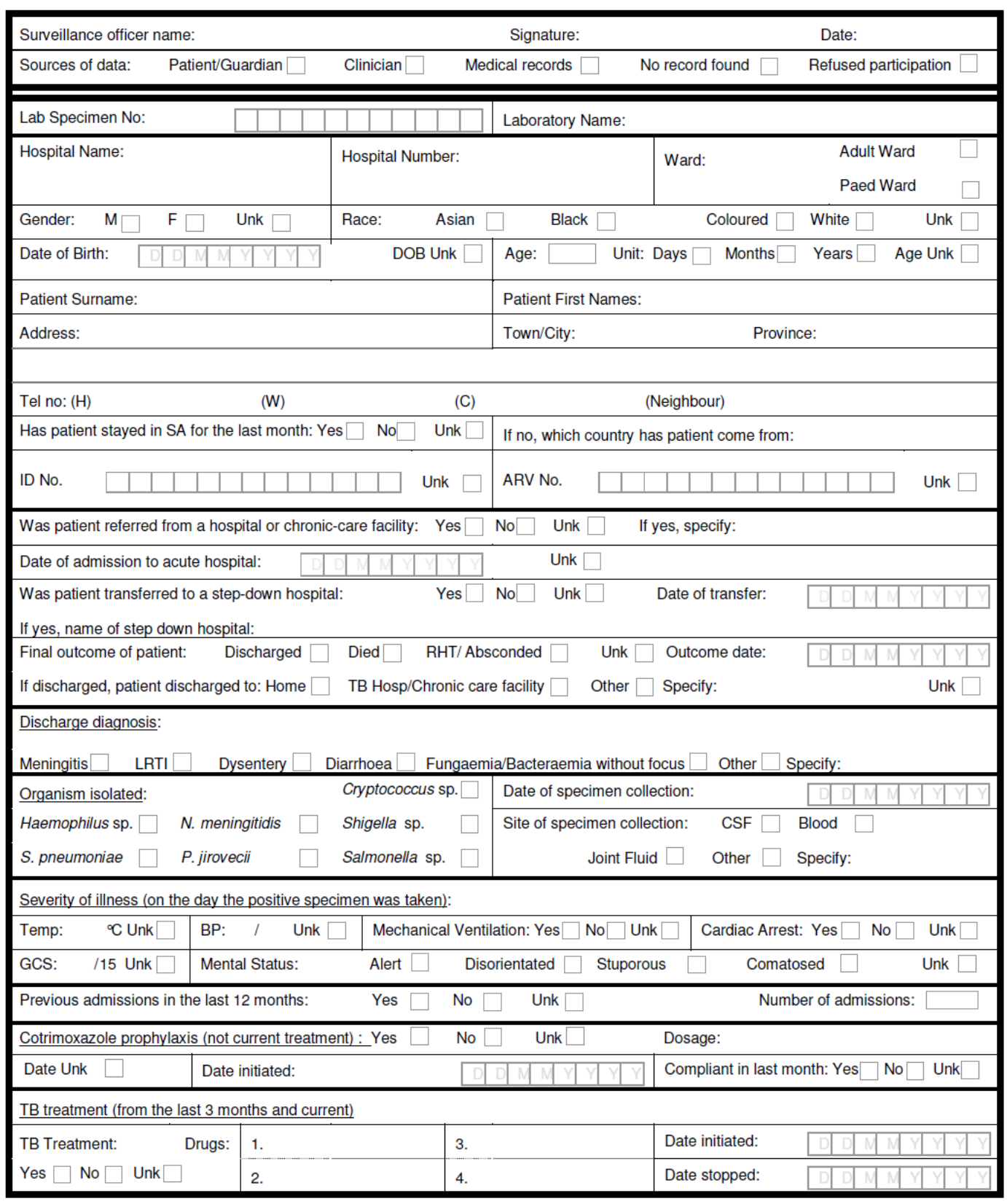


GERMS-SA: National Laboratory-based Surveillance for Enteric, Respiratory and Meningeal

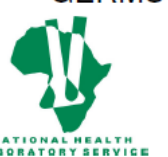

Bacterial and Fungal Diseases in South Africa

Protocol Version 1.4 (January 2009)

Clinical Case Report Form

National Microbiology Surveillance Unit (NMSU)

Laboratory Specimen Number:

TEL: 0113866234 OR $0115550353 \quad$ FAX: 0113866077

\begin{tabular}{ll|l|}
\hline \multicolumn{2}{|l|}{ Immunocompromising conditions: } \\
Alcohol dependency $\square$ & Chronic renal failure $\square$ \\
Asthma & $\square$ & Current smoker \\
Burns & $\square$ \\
CVASStroke & $\square$ & Coronary Artery \\
Disease & $\square$ \\
Diabetes mellitus & $\square$ \\
Cirrhosis/ & $\square$ & Emphysema/COPD \\
liver failure & $\square$ & \\
\hline
\end{tabular}

HIV status prior to this admission:

HIV status at this admission:

For children $<18$ months: HIV PCR Done:

Was the child exposed to HIV?

If HIV unknown, why was patient not tested:

Heart failure
History of head
injury/head surgery
Hydrocephalus with $\square$
VP shunt
Immunoglobulin
deficiency
Immunosuppressive
rx (steroid,chemo)

\section{Kwashiokor/}

Marasmus

Nephrotic syndrome

Sickle cell anaemia

Splenectomy/

asplenia

Systemic Lupus

Systemic Lupus

rx (steroid,chemo)

Pos $\square$ Neg $\square$ Unk

HIV related counseling offered by SO:

Valvular hea

disease

Malignancy

Organ transplant

Other

None

Pos $\square$ Neg $\square$ Unk $\square$

HIV test performed by SO:

Specify

Specify:

Yes $\square$ No $\square$ Unk

Yes $\square$ No $\square$ Unk

If HIV unknown, is there clinical suspicion of HIV: Yes $\square$ No $\square$ Unk

Patient died $\square \quad$ Patient not seen

No guardian

Patient confused/ comatose

Pt referred for VCT elsewhere

\begin{tabular}{|c|c|c|c|c|c|}
\hline Clinical markers of HIV: & Diarrhoea $>$ 10days & Oral candidiasis & Suspected PCP & & None \\
\hline & Kaposis sarcoma $\square$ & Tuberculosis & HIV wasting & & Unk \\
\hline \multirow[t]{2}{*}{ CD4 count closest to specimen collection date: } & Absolute: & Unk & \multirow[b]{2}{*}{ Date taken: } & & \\
\hline & Percentage: & Unk & & \begin{tabular}{l|l|l|l|l|l|l}
$D$ & $D$ & $M$ \\
\end{tabular} & \\
\hline Viral load closest to specimen collection date: & $<400 \square \quad 400-10,000$ & $>10,000$ & Date taken: & \begin{tabular}{l|l|l|}
$D$ & $D$ & $M$ \\
\end{tabular} & \\
\hline Any antiretroviral use: $\quad$ Yes $\square$ No $\square$ Unk $\square$ & If yes: Current & Previous & Perinatal & & Unk \\
\hline If HIV positive and no current ARV use, has the & atient been referred to & RV clinic: & No & Died & Unk \\
\hline
\end{tabular}

PLEASE COMPLETE RELEVANT SECTIONS FOR SPECIFIED ORGANISMS

Haemophilus spp., S. pneumoniae, N. meningitidis, Salmonella spp., Shigella spp. ONLY

Number of children, $<18$ years, living with patient:

None

Number

Have any of these children been hospitalised in the last 3 months:

Antibiotic use prior to this specimen collection date:

$A B X$ in $24 \mathrm{hr}$ before specimen:

Yes $\square$ No $\square$ Unk

Date initiated:

Name of antibiotic:

1.2.

3.

3. 4

Other $\mathrm{ABX}$ in last 2 months:

Yes $\square$ No $\square$ Unk $\square$ In last 30 days:

Name of antibiotic:

2.

In last 30 to 60 days:

Place of safety

No $\square \quad$ Unk

Antibiotic use in hospital during this admission (excluding TB therapy)

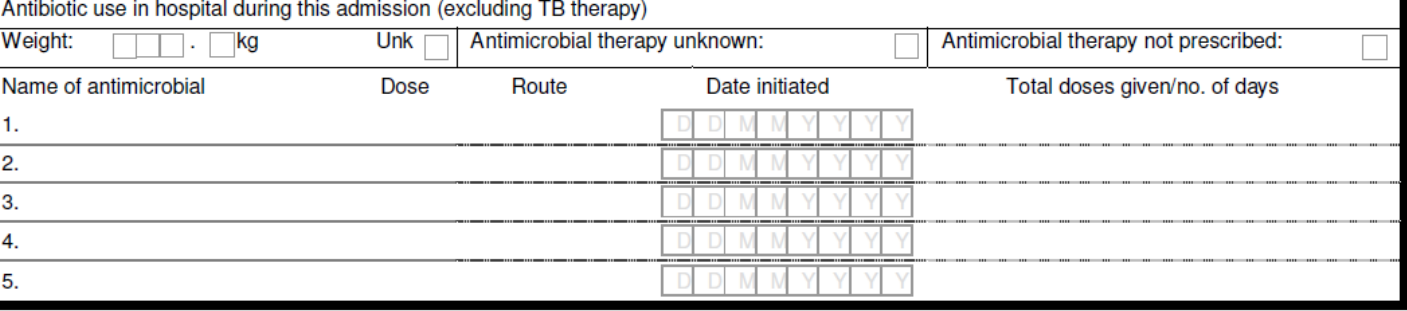


Neonatal IPD in South Africa: 2003 - 2008

GERMS-SA: National Laboratory-based Surveillance for Enteric, Respiratory and Meningeal

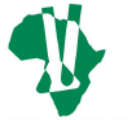

Bacterial and Fungal Diseases in South Africa

Protocol Version 1.4 (January 2009)

Clinical Case Report Form

National Microbiology Surveillance Unit (NMSU)

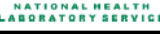

TEL: 0113866234 OR $0115550353 \quad$ FAX: 0113866077

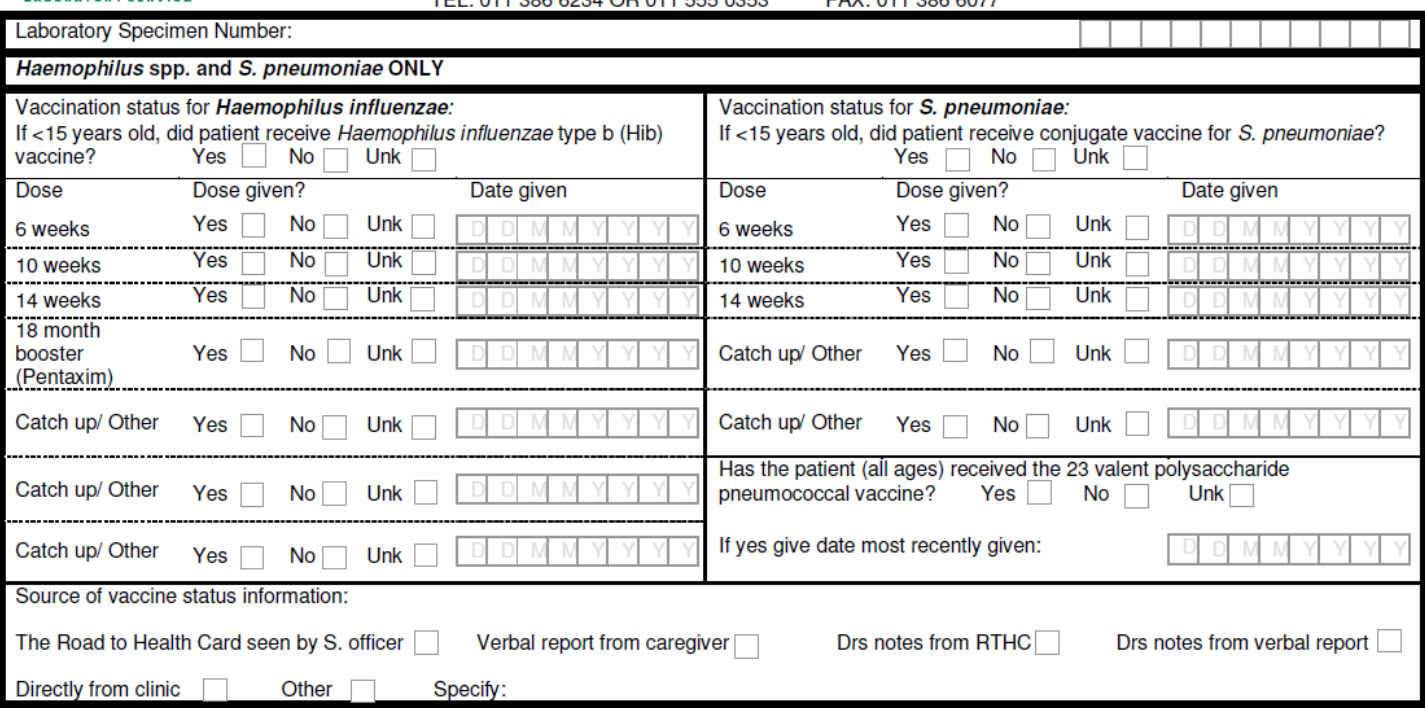

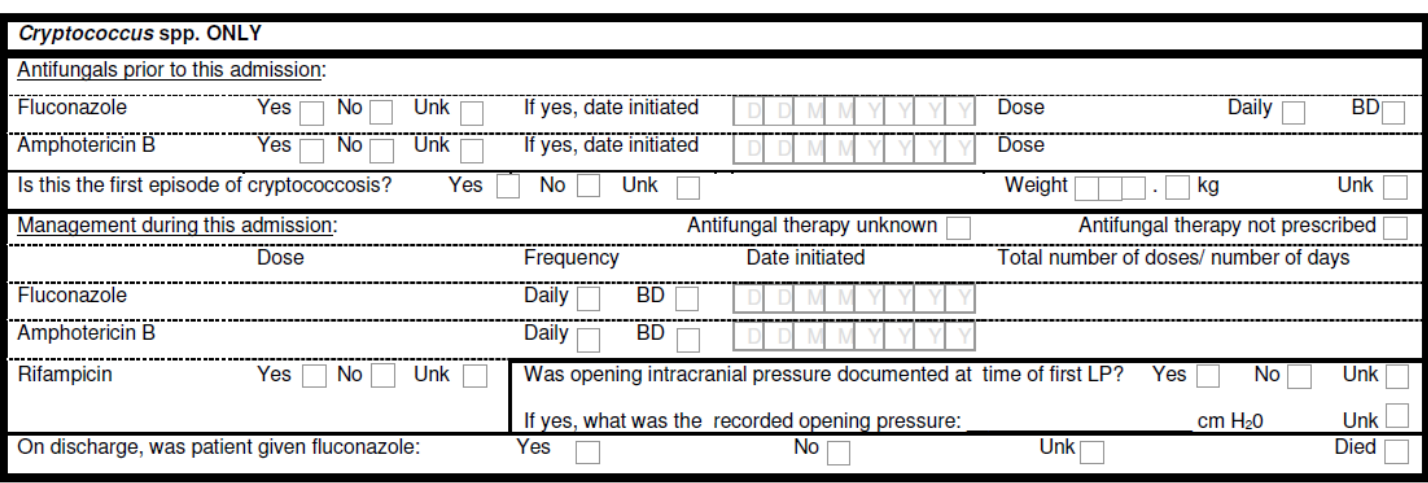

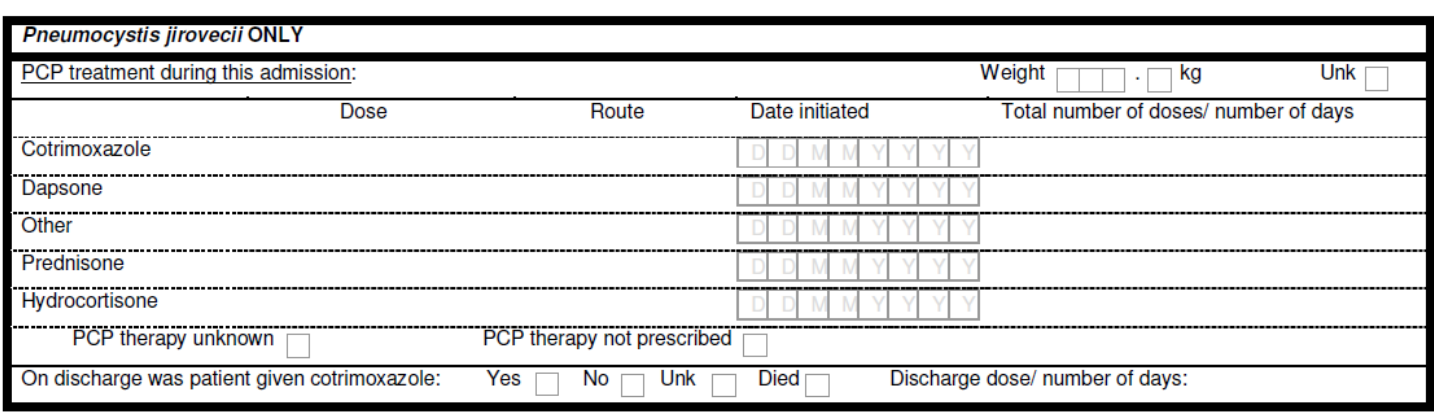

